\title{
Electrokinetic Effects on the Transport of Charged Analytes in Biporous Media with Discrete Ion-Permselective Regions by
}

Felix Leinweber, Matthias Pfafferodt, Andreas Seidel-Morgenstern, Ulrich Tallarek

\section{Contents}

A MATLAB scripts $\quad 3$

A.1 ./main.m . . . . . . . . . . . . . . . . . . . . 3

A.2./femlab/change_var.m .................... 5

A.3 ./femlab $/$ fem_init.m . . . . . . . . . . . . . . . . . 6

A.4./femlab $/$ fem_movie.m . . . . . . . . . . . . . . . . . 14

A.5./femlab/fem_NS.m . . . . . . . . . . . . . . . . 16

A.6 ./femlab/fem_postplot.m . . . . . . . . . . . . . . . . 18

A.7 ./femlab/fem_static.m . . . . . . . . . . . . . . . . 19

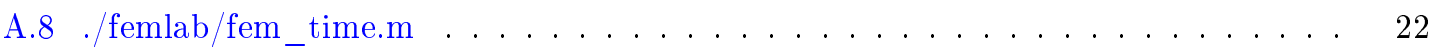

A.9./functions $/$ check_file.m . . . . . . . . . . . . . . . . . 23

A.10./functions /get_var.m . . . . . . . . . . . . . . . . . . . 24

A.11./functions /getminmax.m . . . . . . . . . . . . . . . . 25

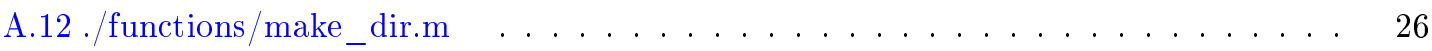

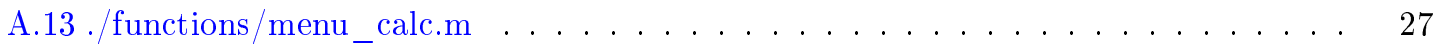

A.14./functions $/$ menu_config.m . . . . . . . . . . . . . . . . . . 27

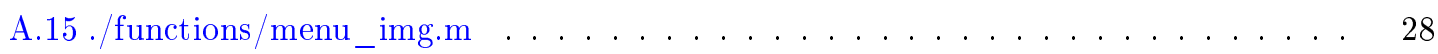

A.16./functions/print_config.m . . . . . . . . . . . . . . . . 31

A.17./functions $/$ print_img_info.m . . . . . . . . . . . . . . 32

A.18./functions $/$ save_img.m . . . . . . . . . . . . . . . . 32

A.19./modell/modell_compare_crossplot.m . . . . . . . . . . . . 33

A.20./modell/modell_compare_experiment.m . . . . . . . . . . . . . 34

A.21./modell/modell_compare_integral.m . . . . . . . . . . . . . 37

A.22./modell/modell_compare_strom.m . . . . . . . . . . . . . . . 38

A.23./modell/modell_compare_subplot.m . . . . . . . . . . . . . . . 40

A.24./modell/modell_compare_surface.m . . . . . . . . . . . . . . . 41

A.25./modell/modell_time_crossplot.m . . . . . . . . . . . . . . . . . 42

A.26./modell $/$ modell_static.m . . . . . . . . . . . . . . . . . 43

A.27./modell $/$ modell_time.m . . . . . . . . . . . . . . . . . . 44

A.28./modell $/$ modell_time_movie.m . . . . . . . . . . . . . . . 46

A.29 ./modell $/$ modell_time_subplot.m . . . . . . . . . . . . . . . . 46

A.30./modell/modell_time_surface.m . . . . . . . . . . . . . . 47 


\section{A MATLAB scripts}

\section{A.1 ./main.m}

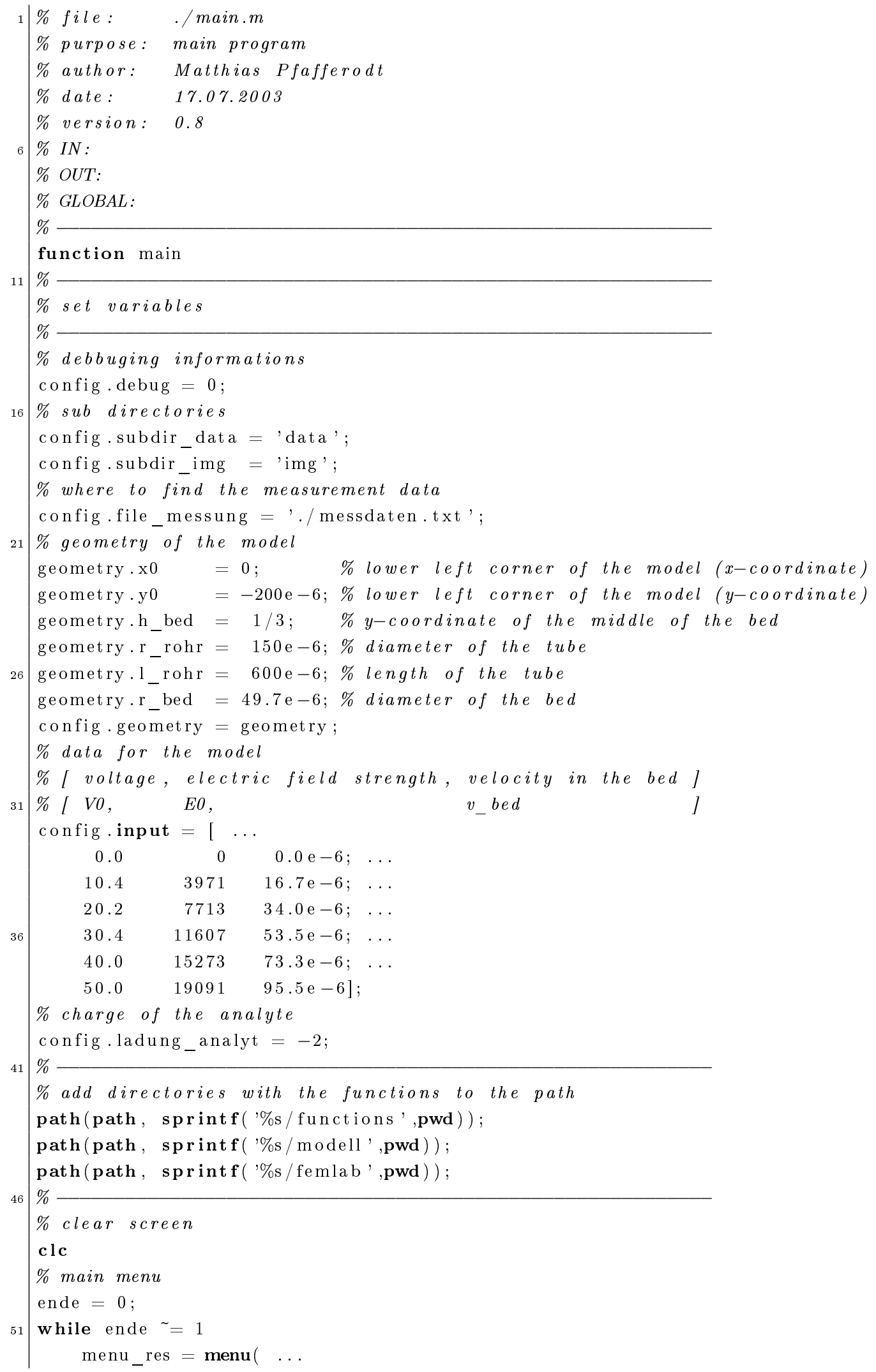




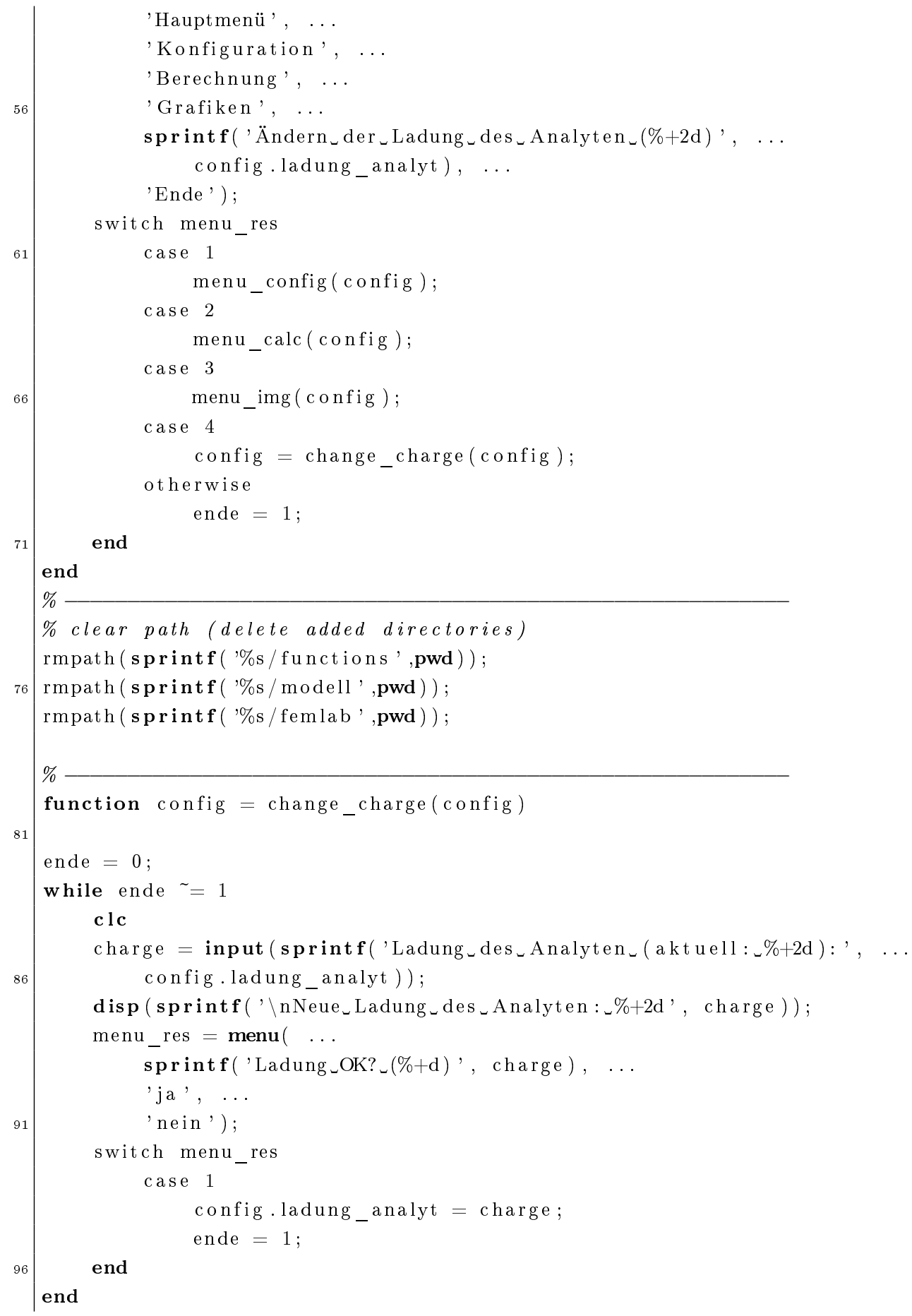

\section{A.2 ./femlab/change_var.m}

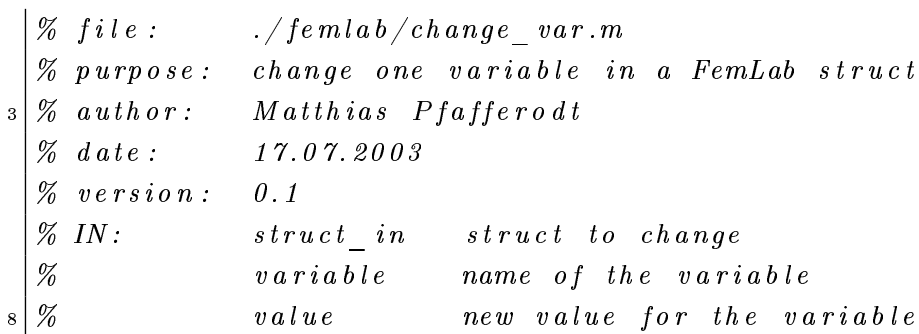




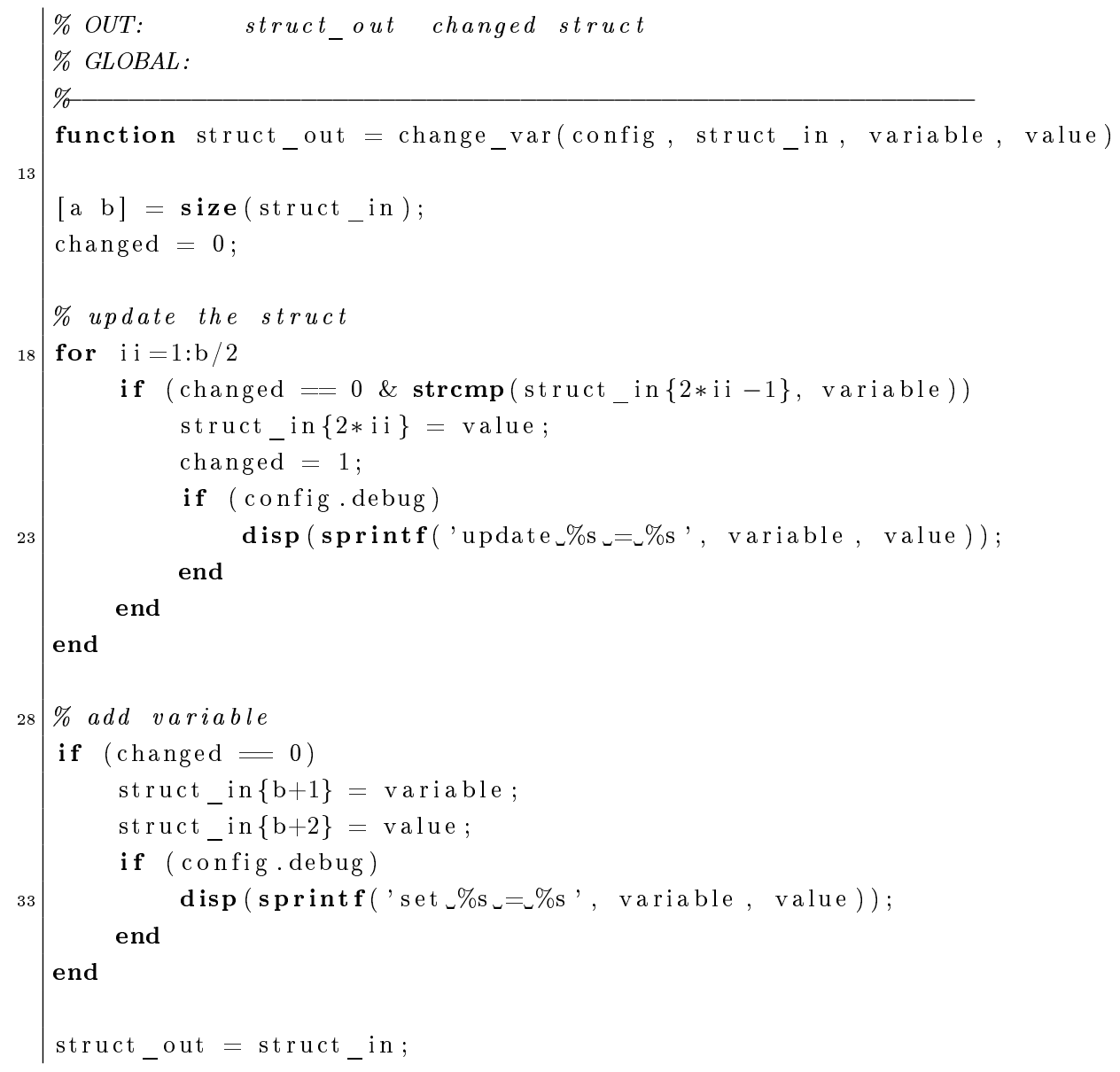

\section{A.3 ./femlab/fem_init.m}

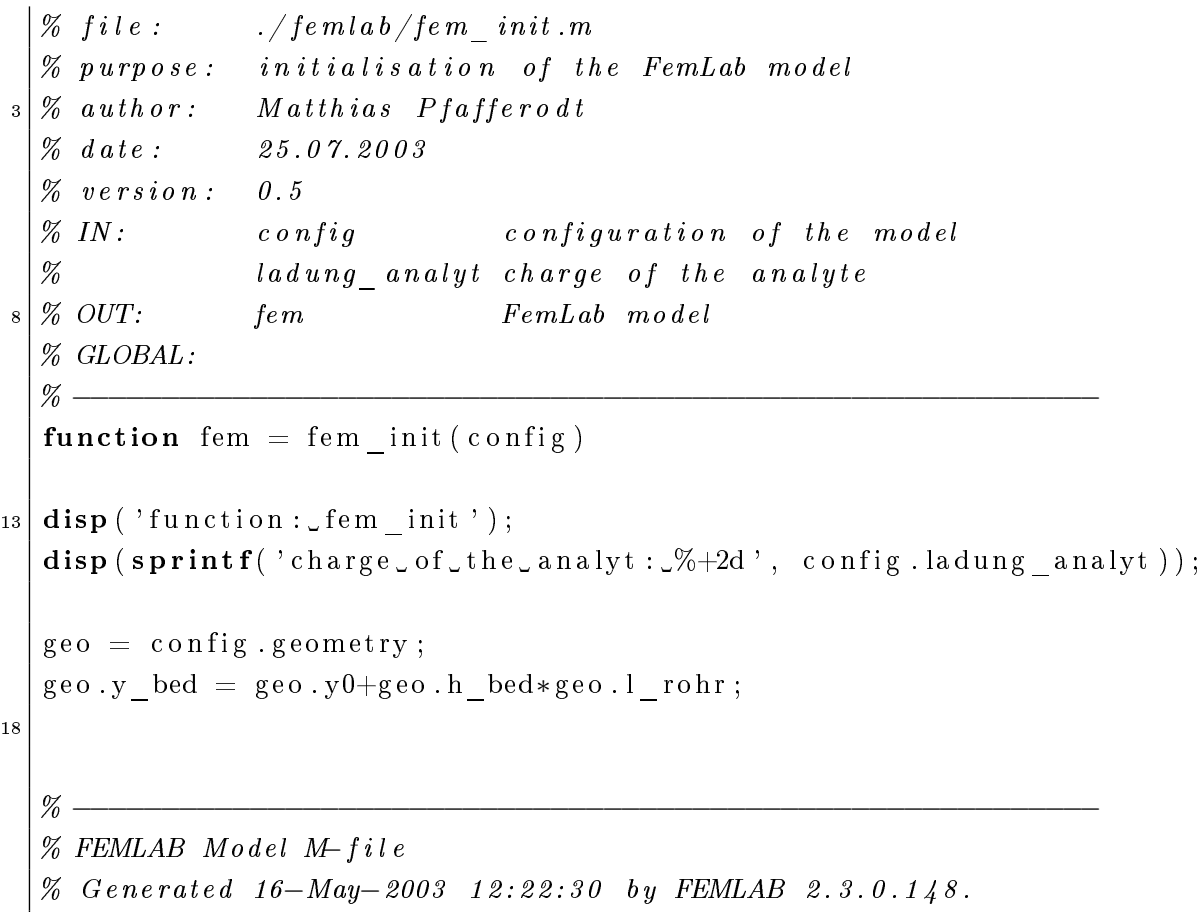




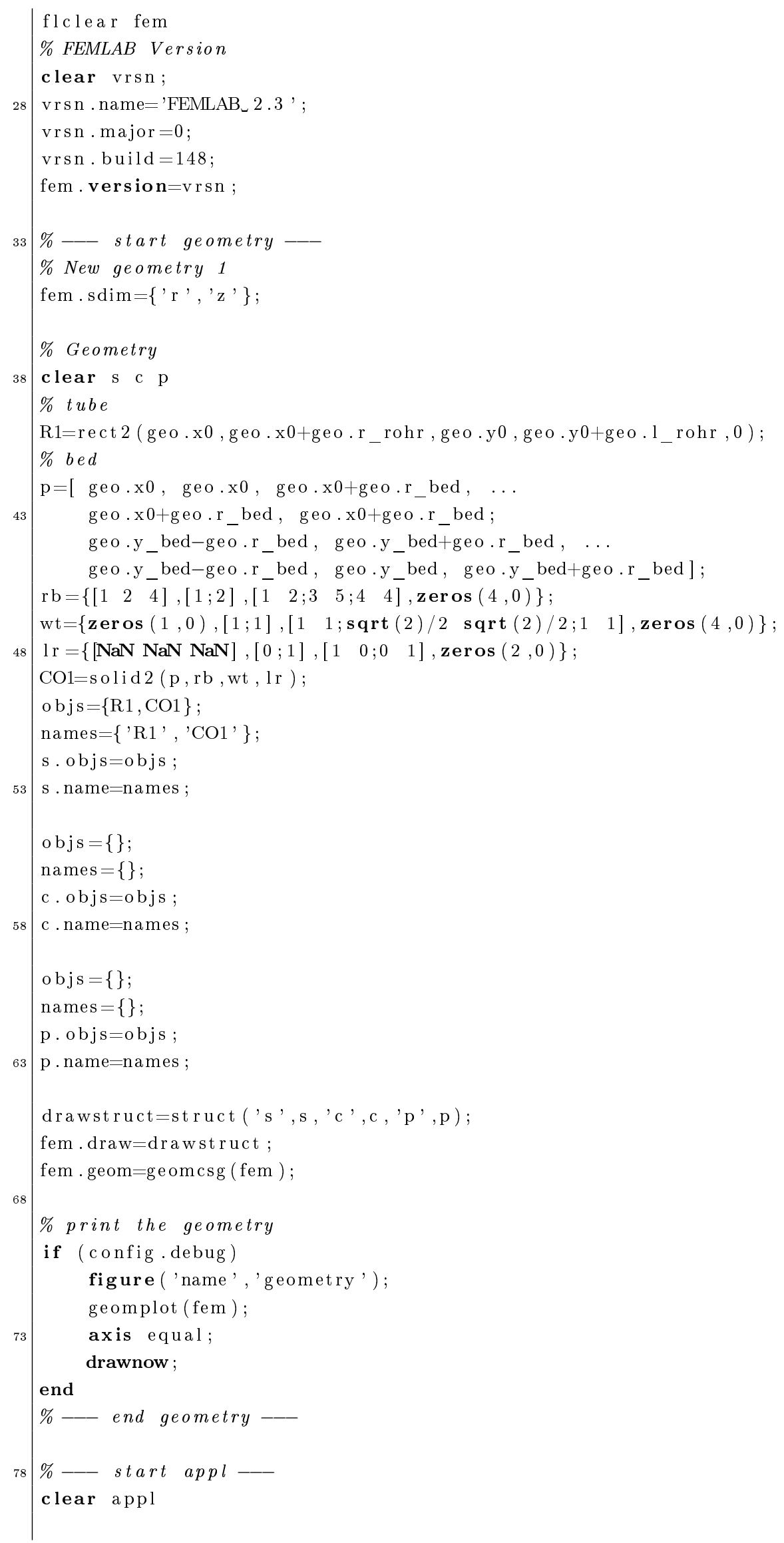




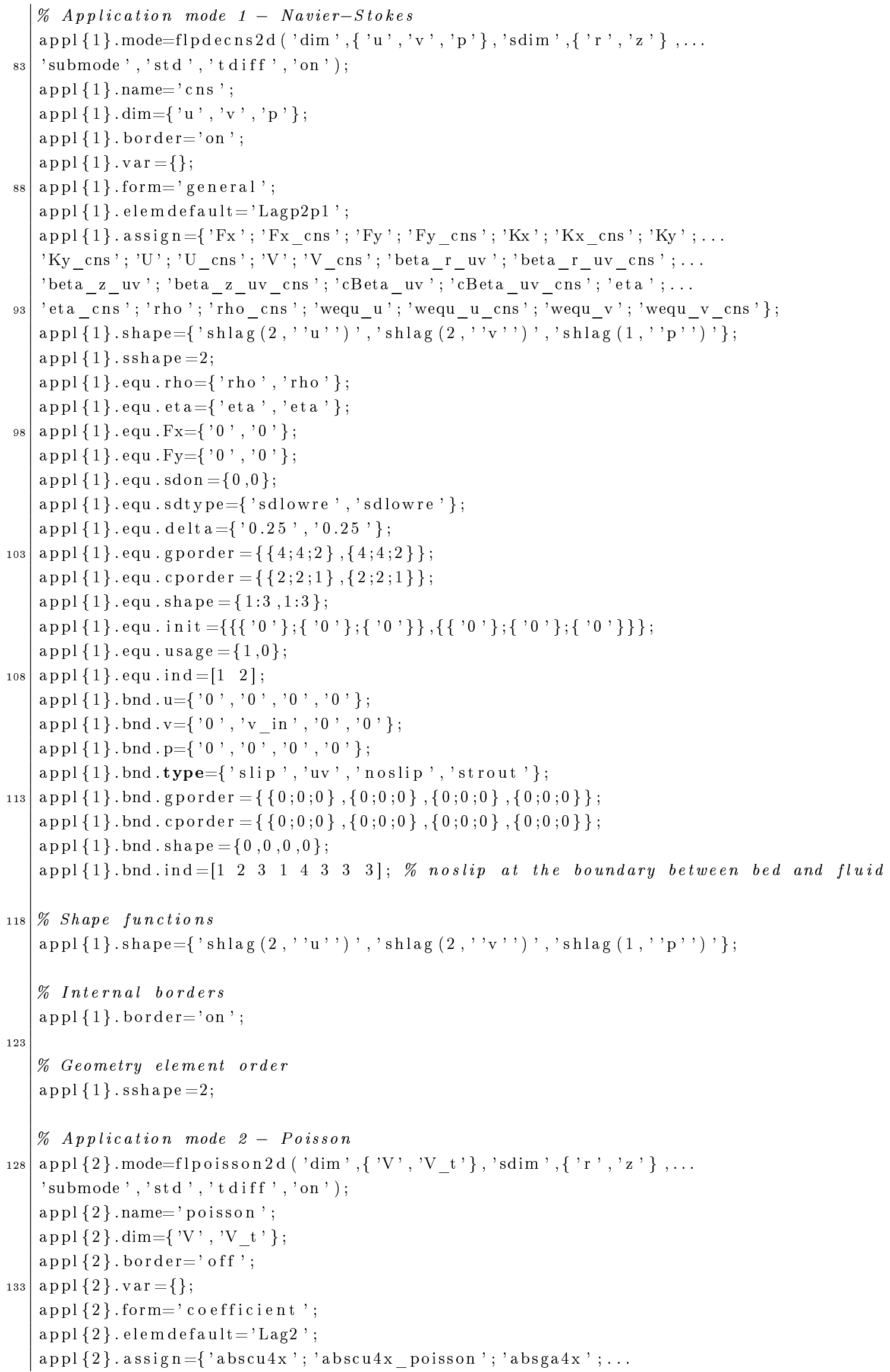




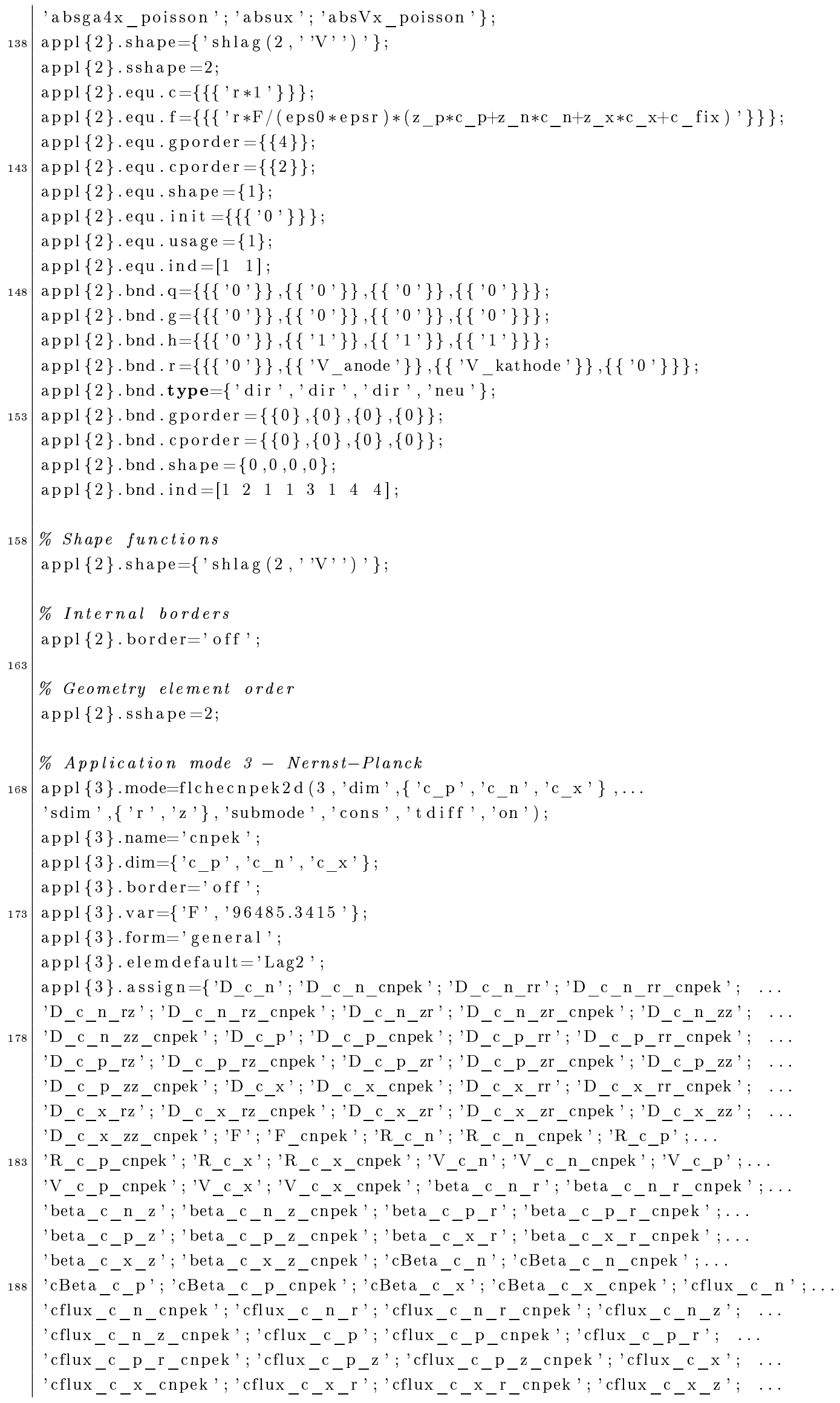




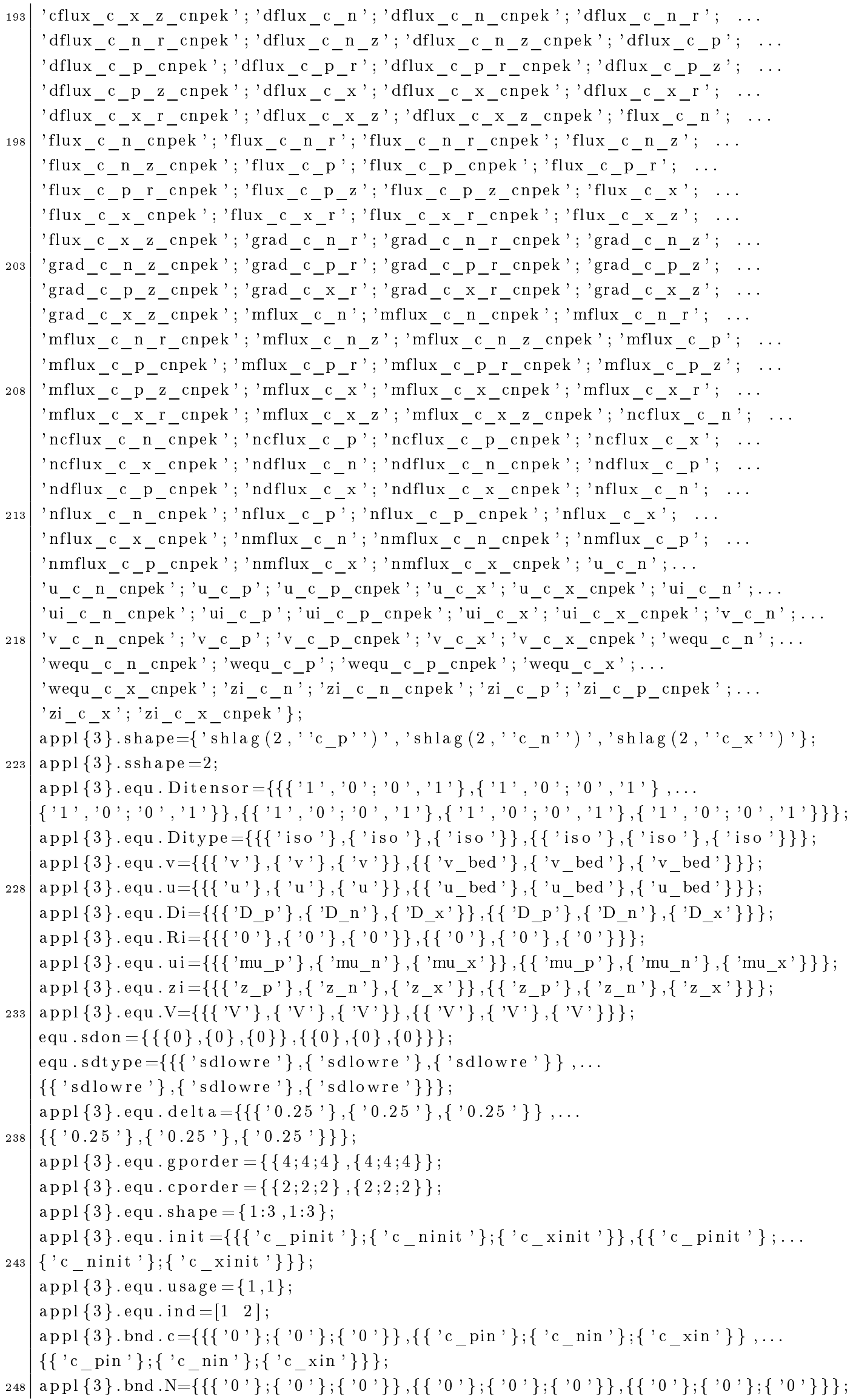




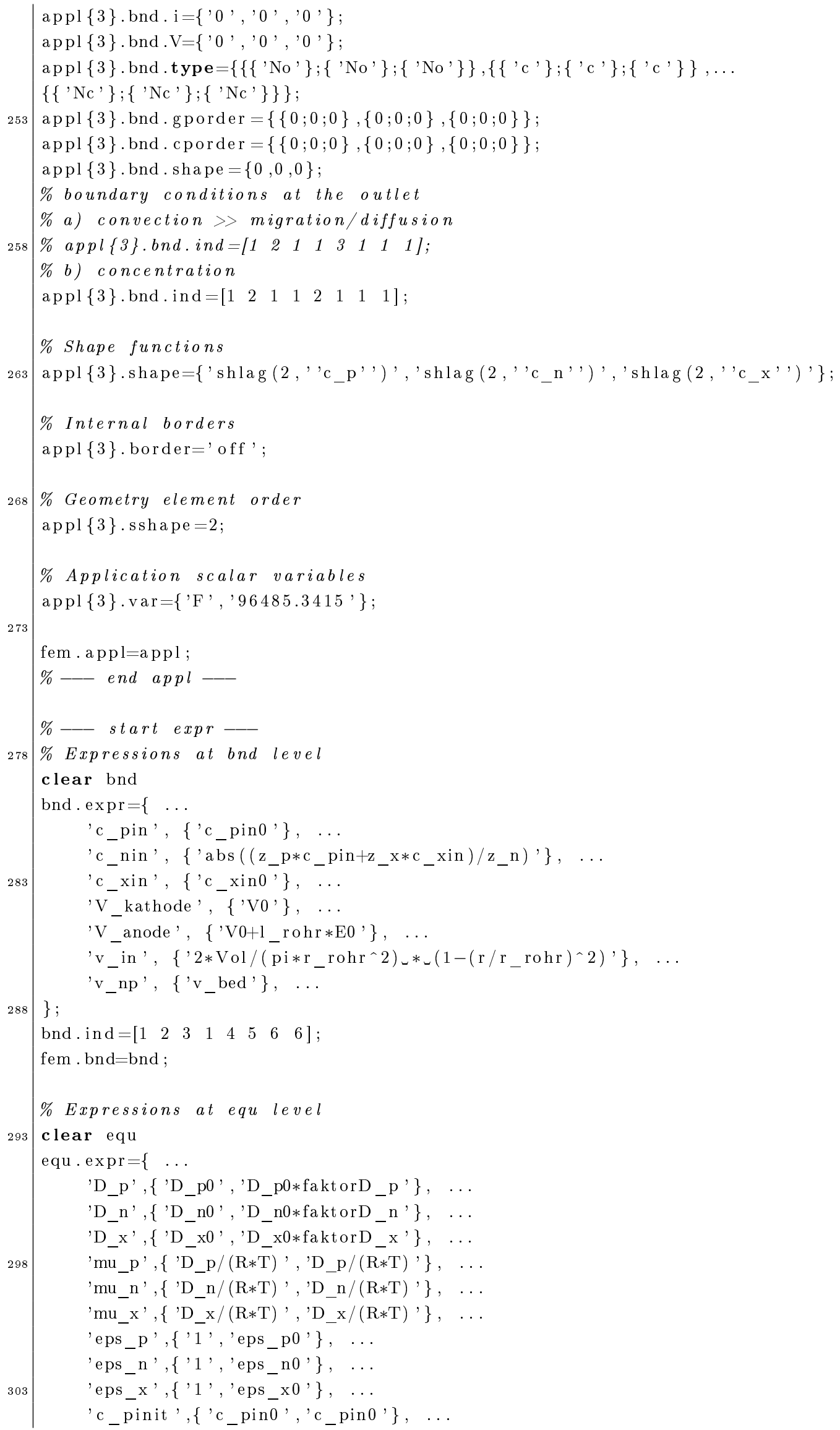




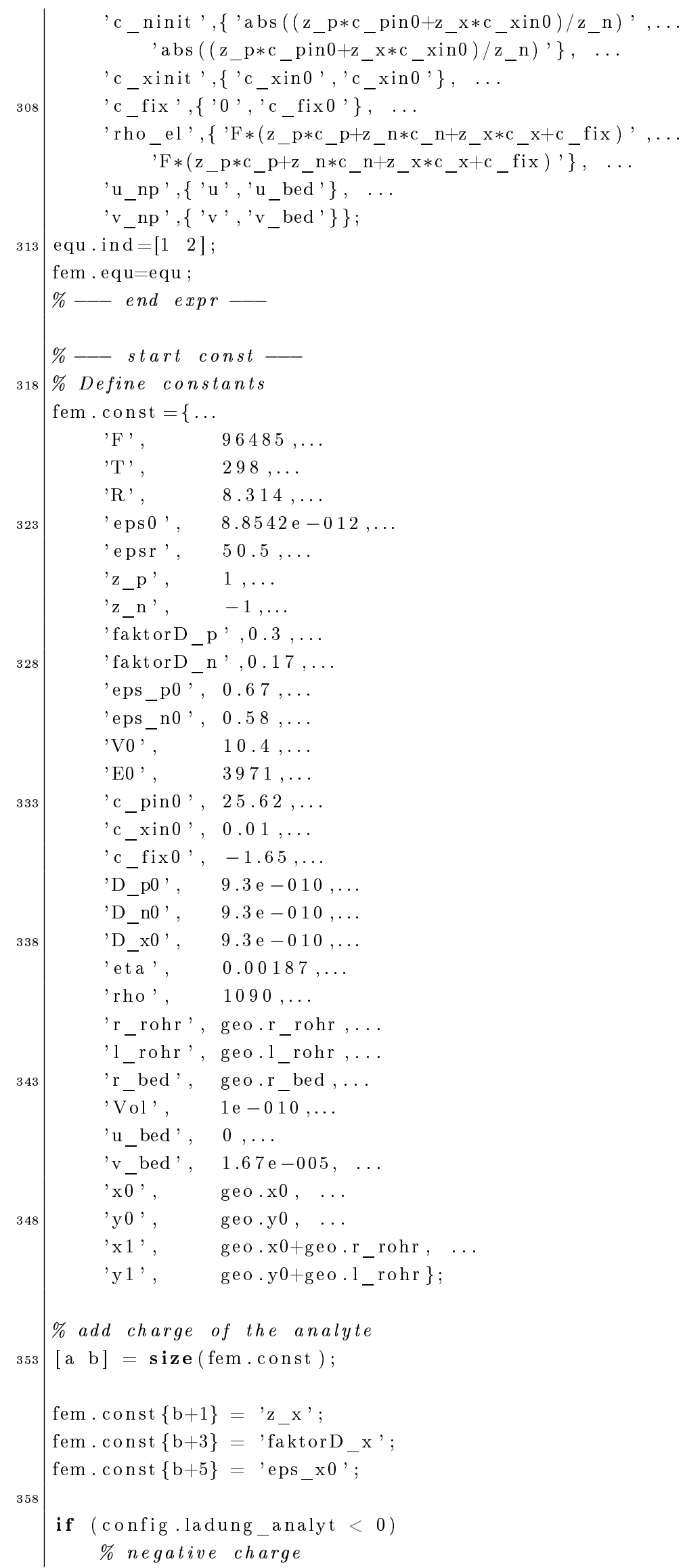




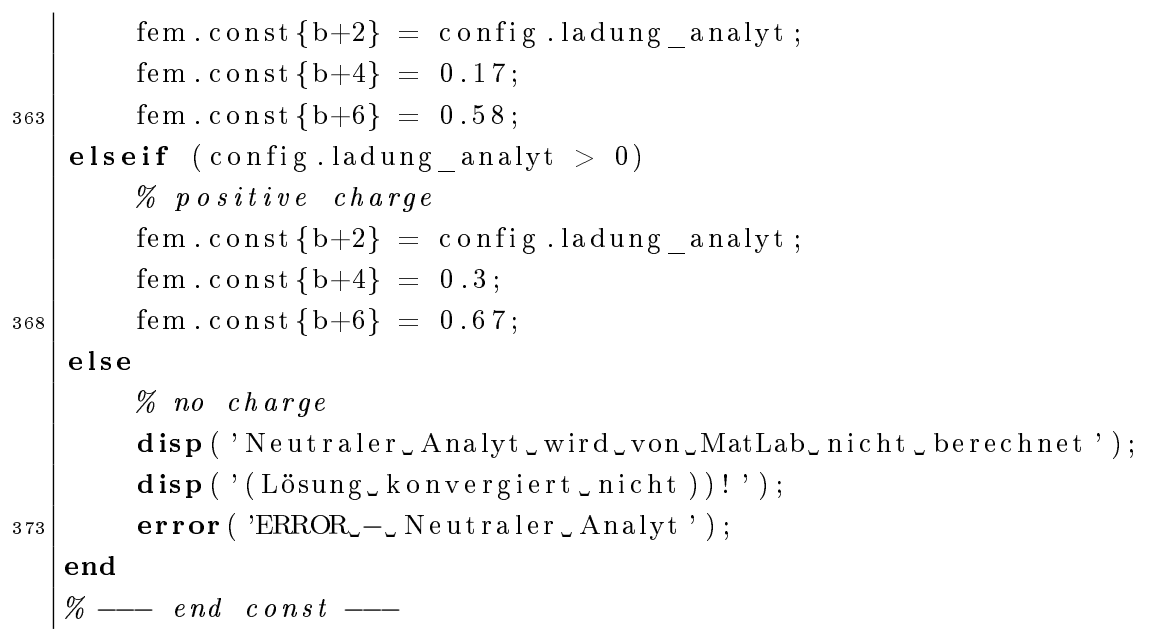

\section{A.4 ./femlab/fem movie.m}

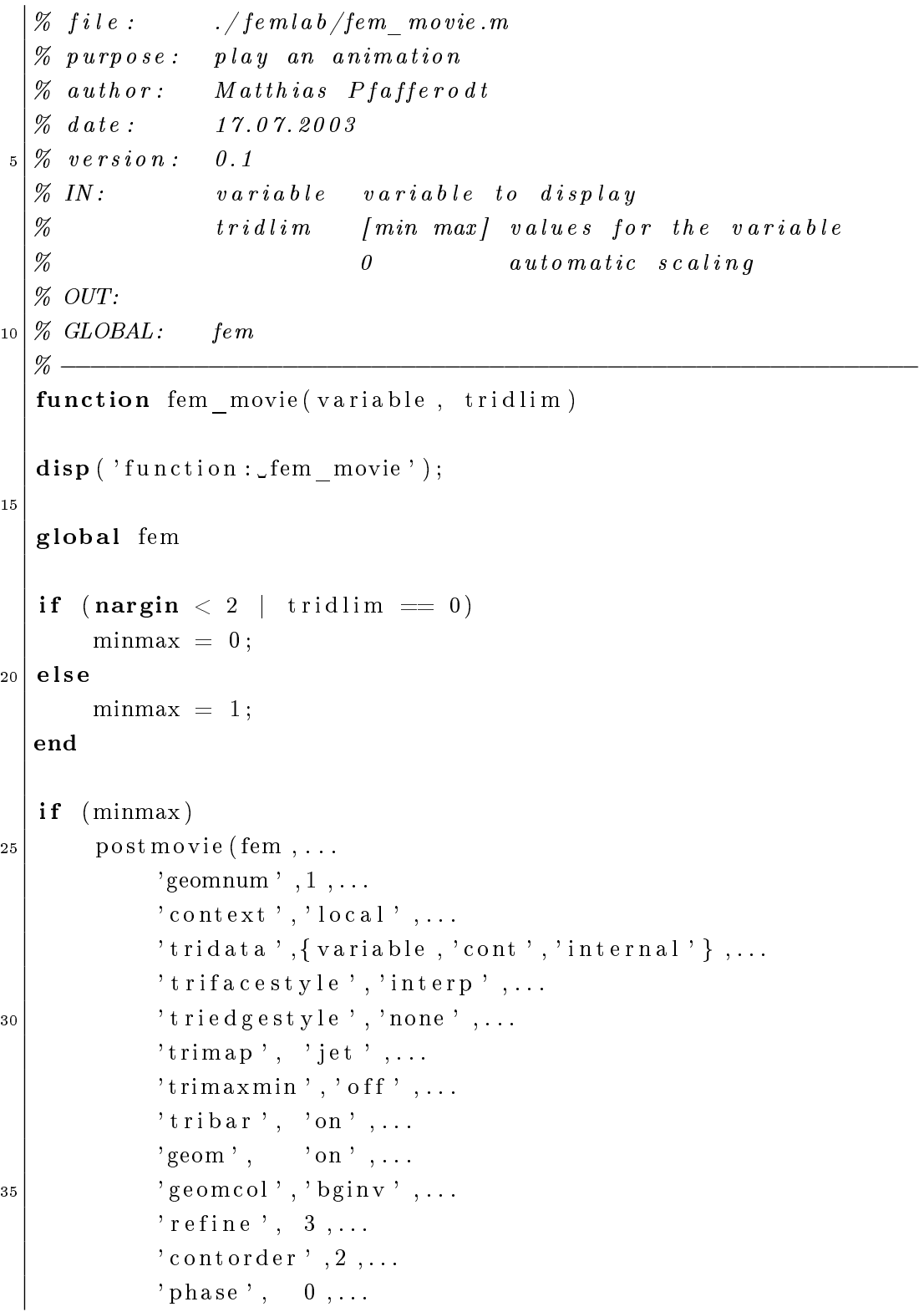




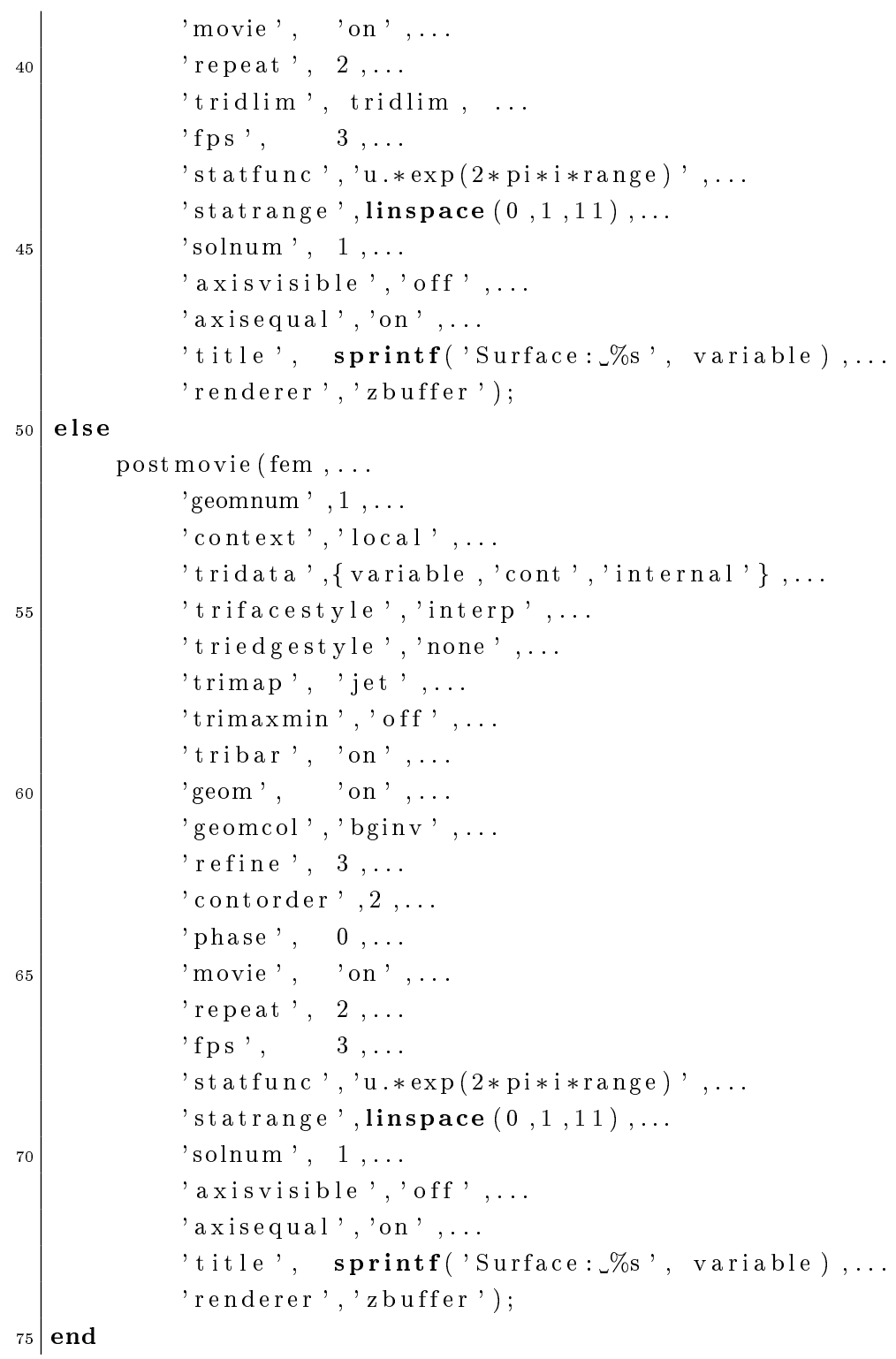

\section{A.5 ./femlab/fem_NS.m}

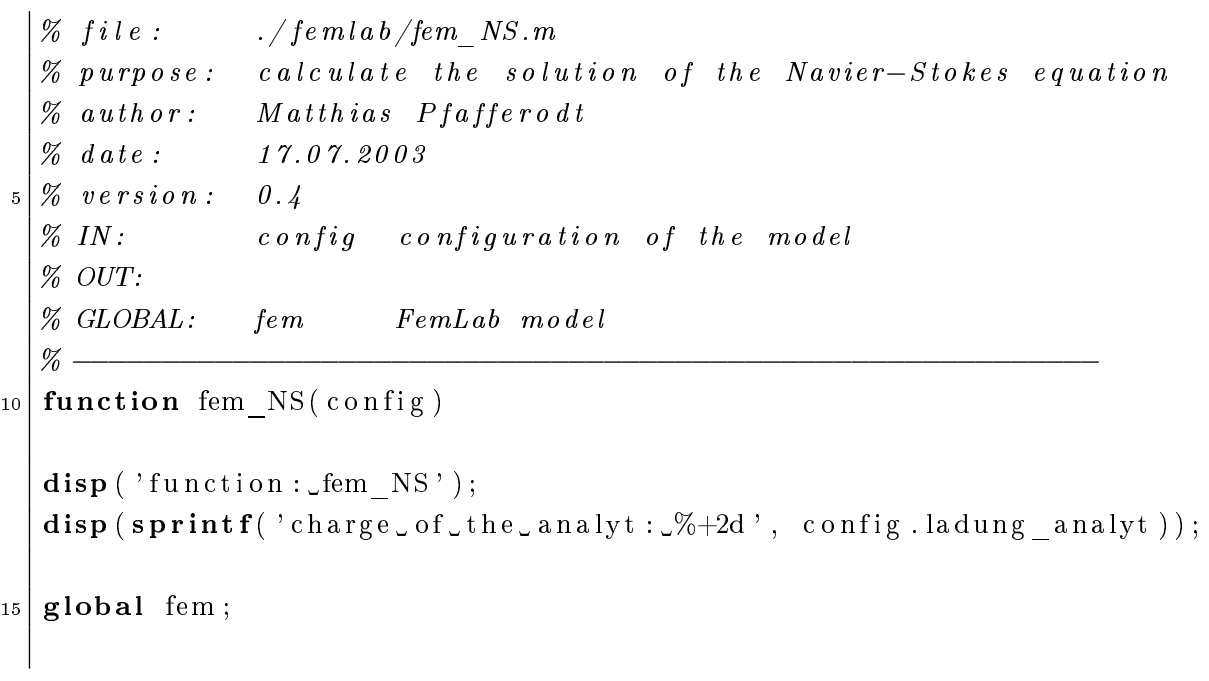




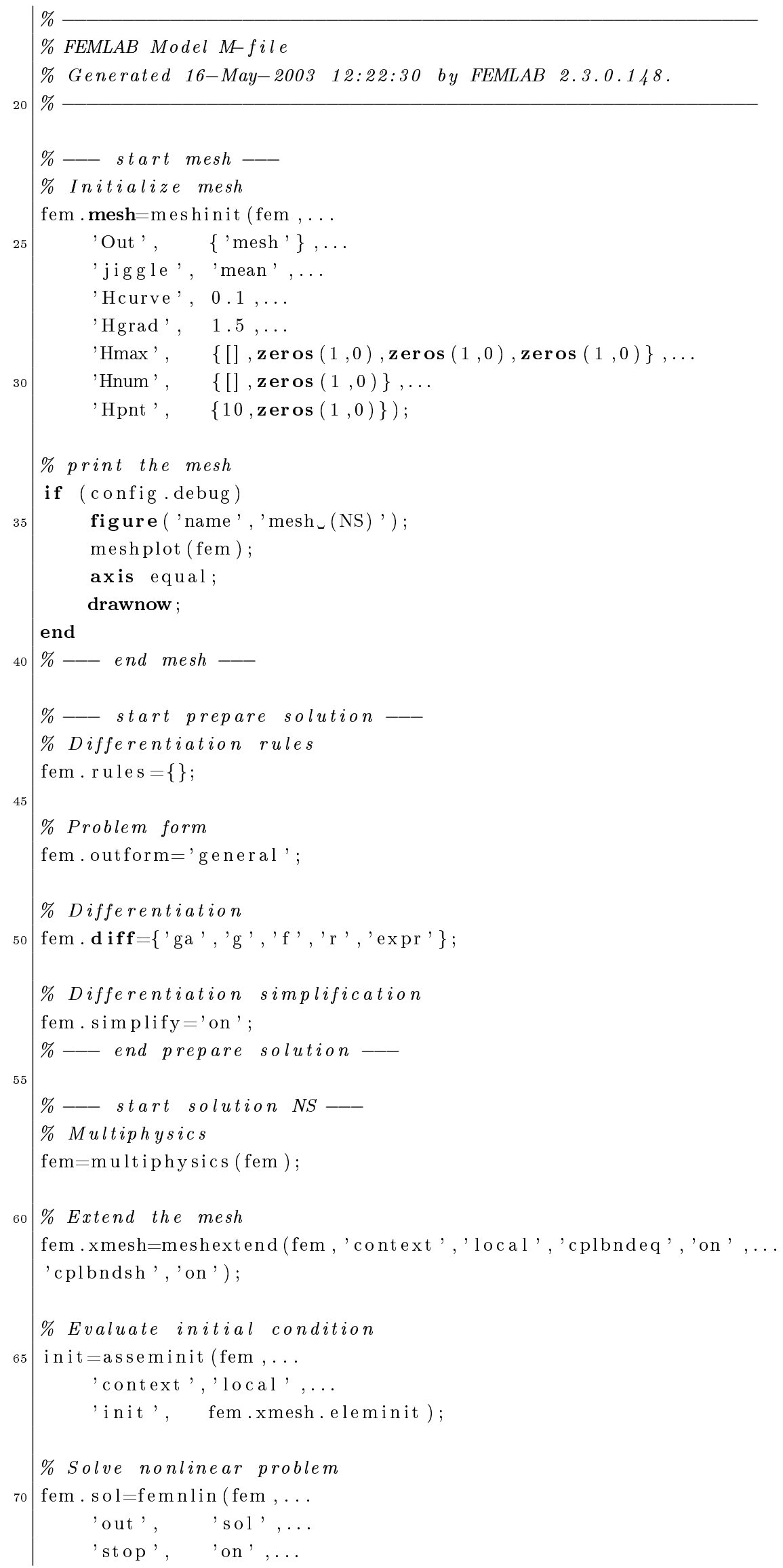




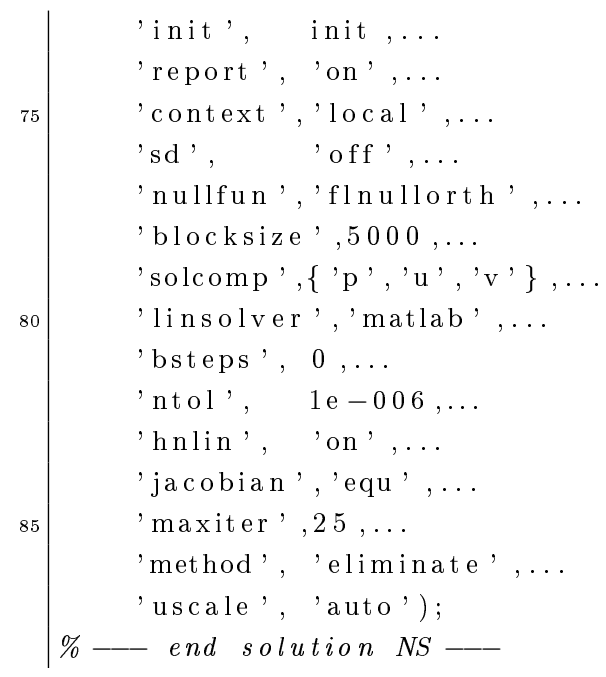

\section{A.6 . femlab/fem_postplot.m}

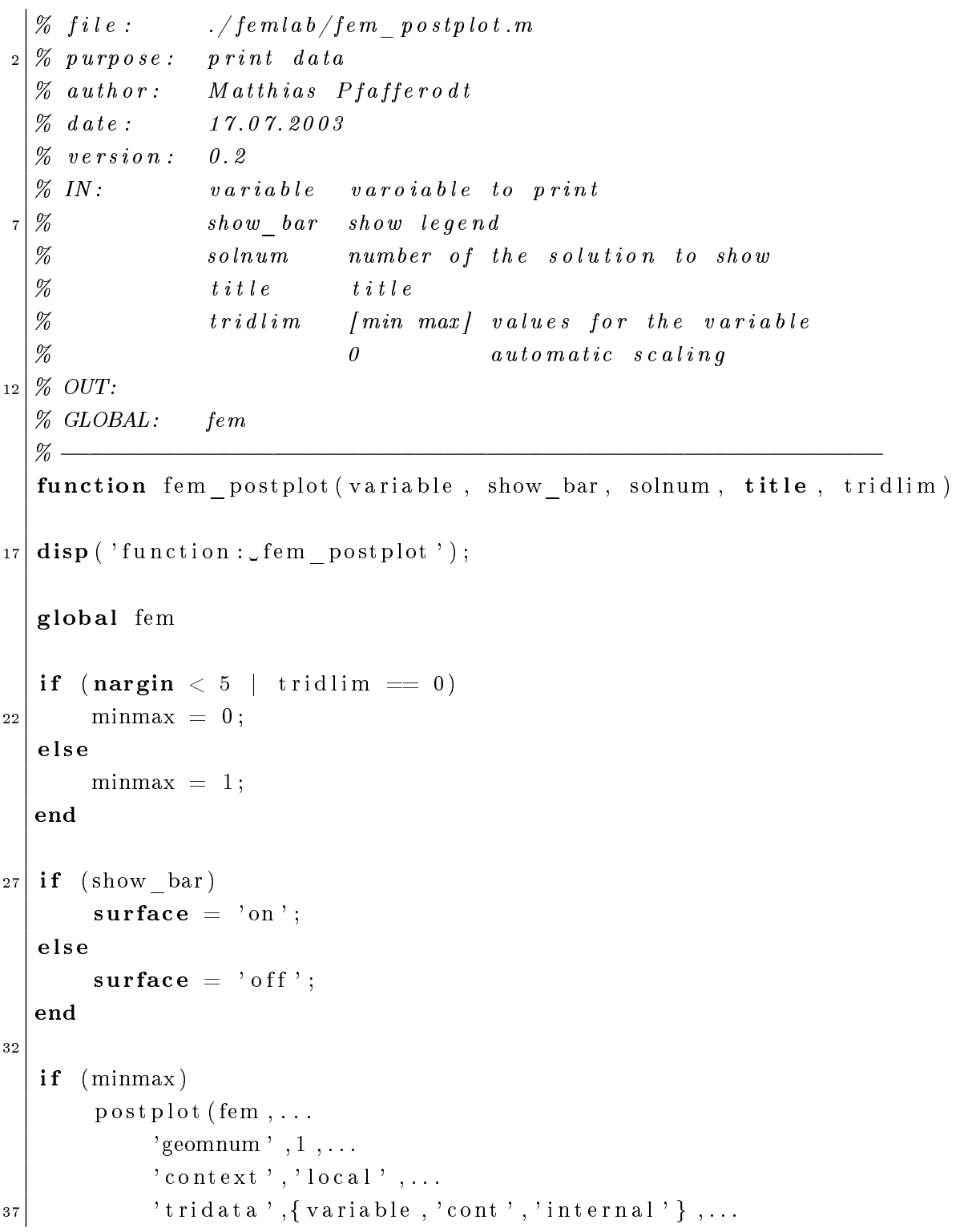




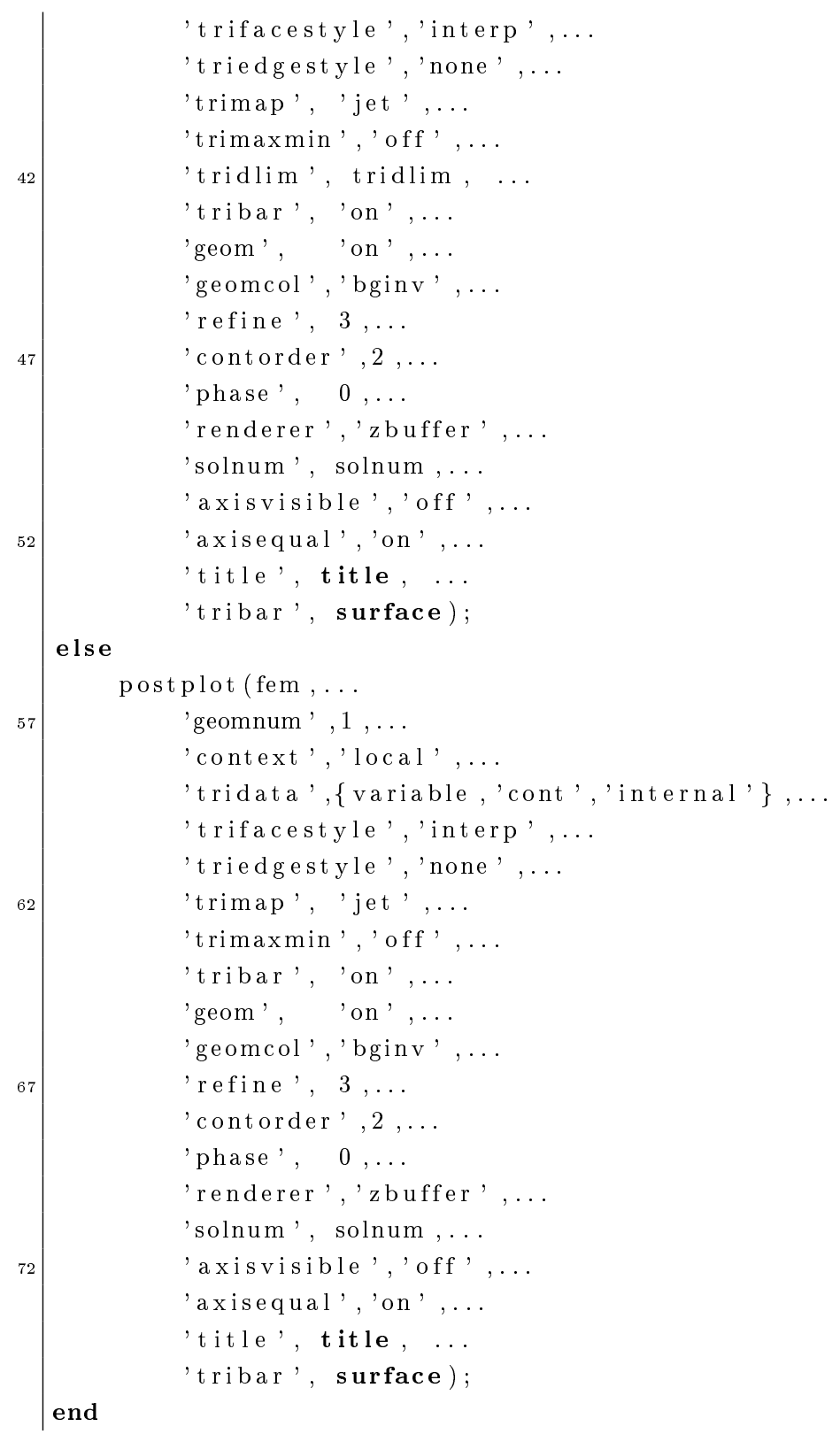

\section{A.7 ./femlab/fem static.m}

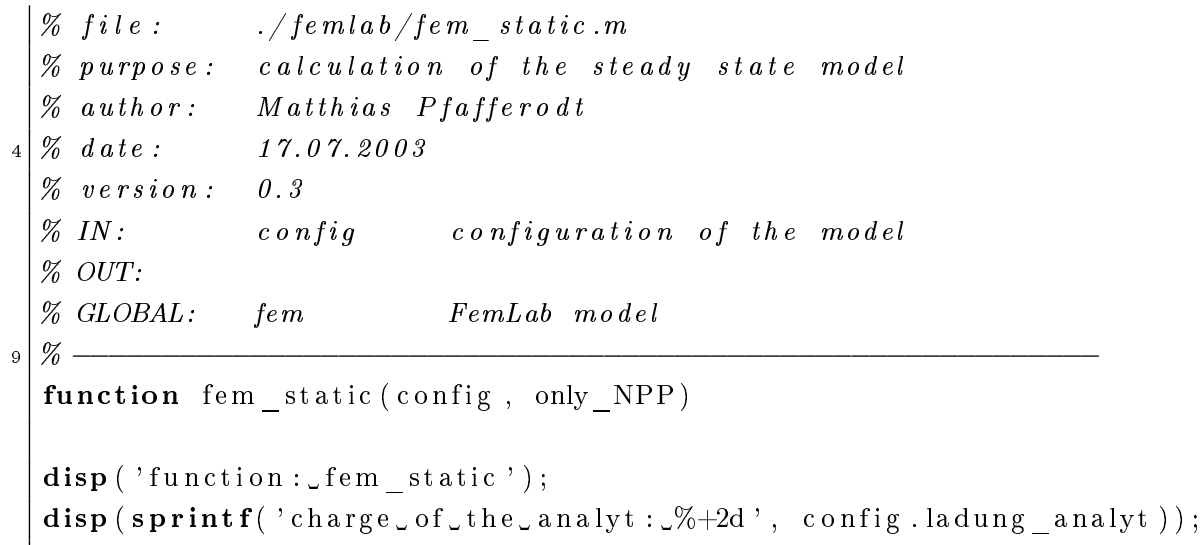




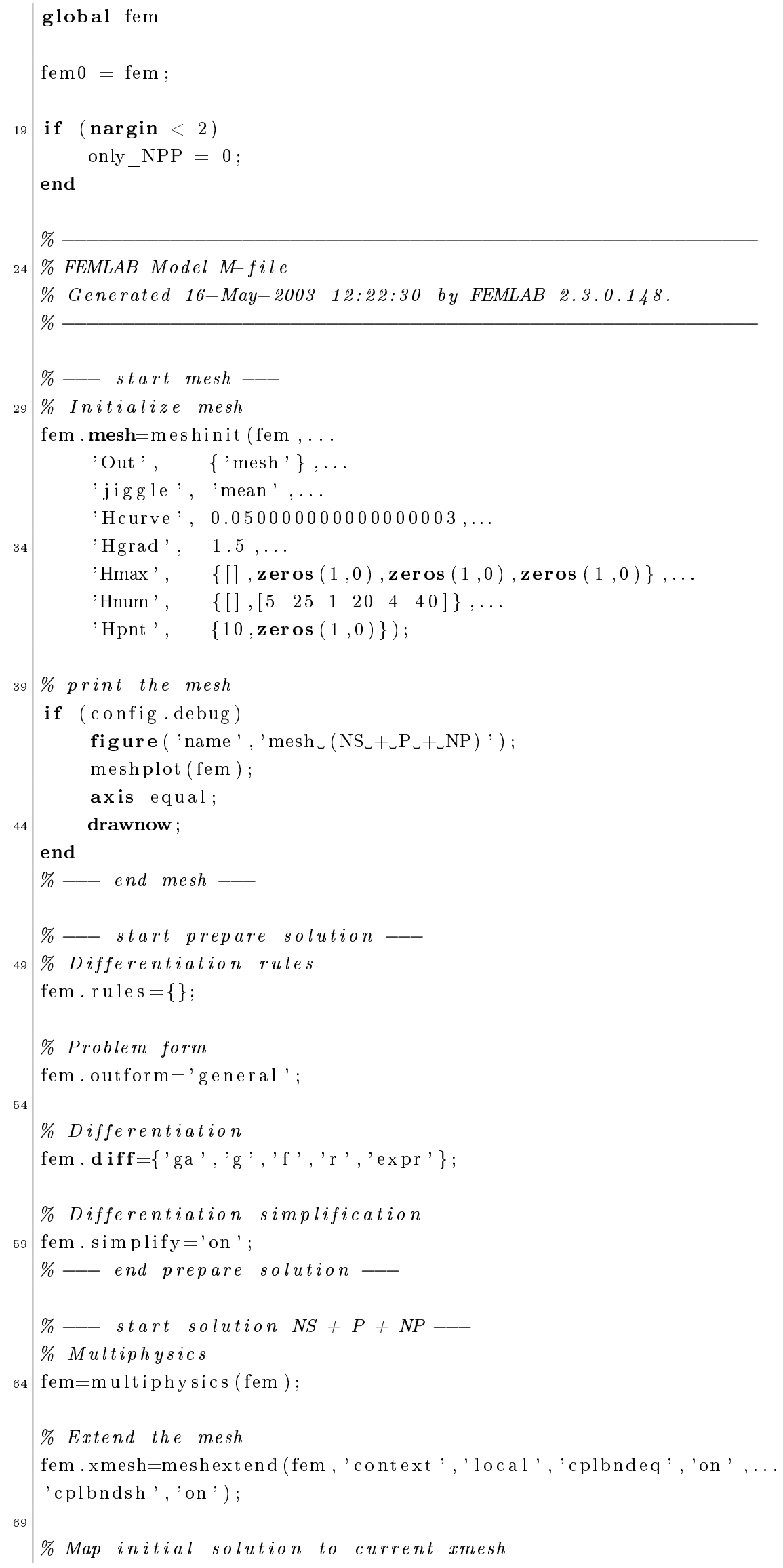




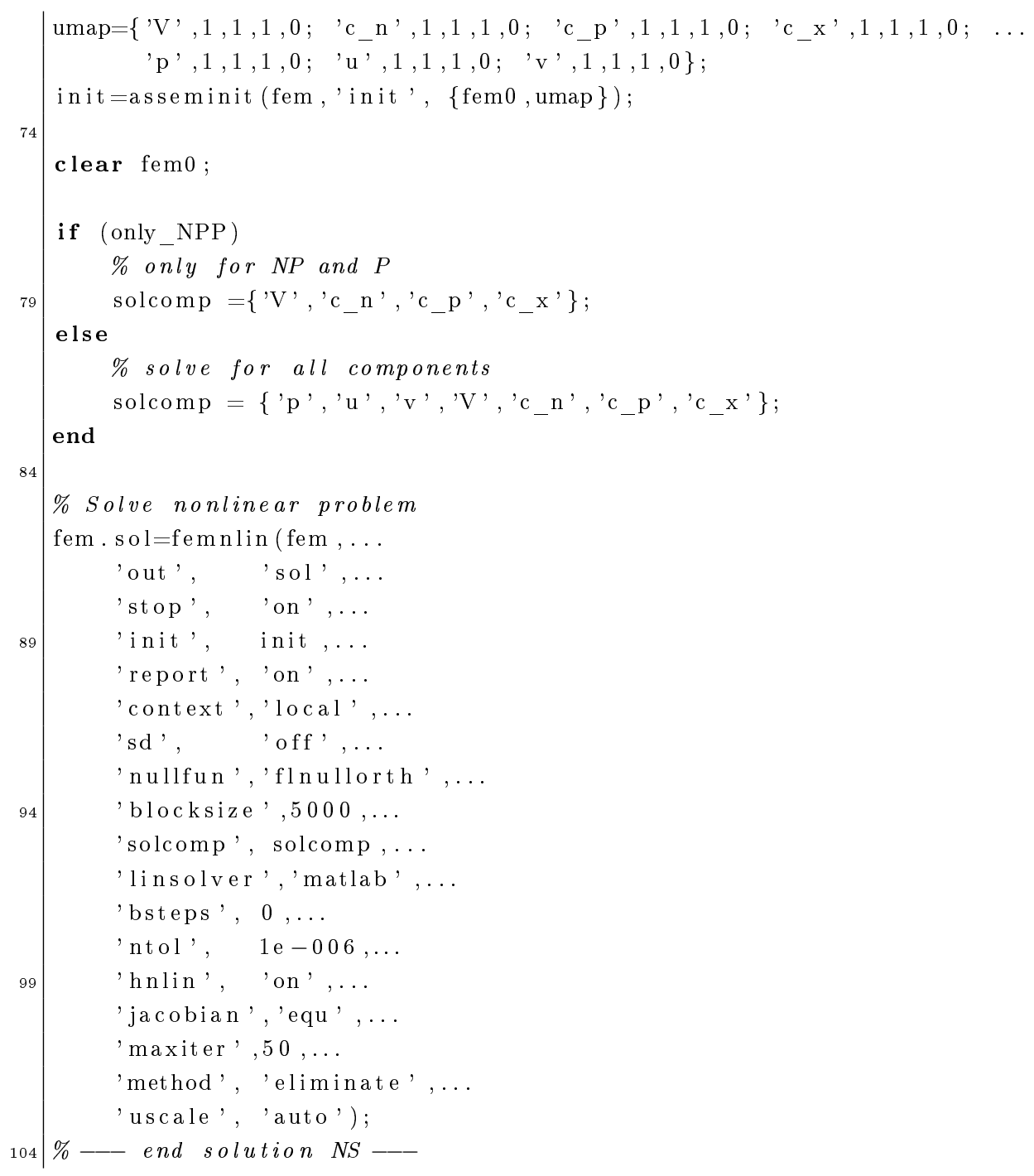

\section{A.8 ./femlab/fem_time.m}

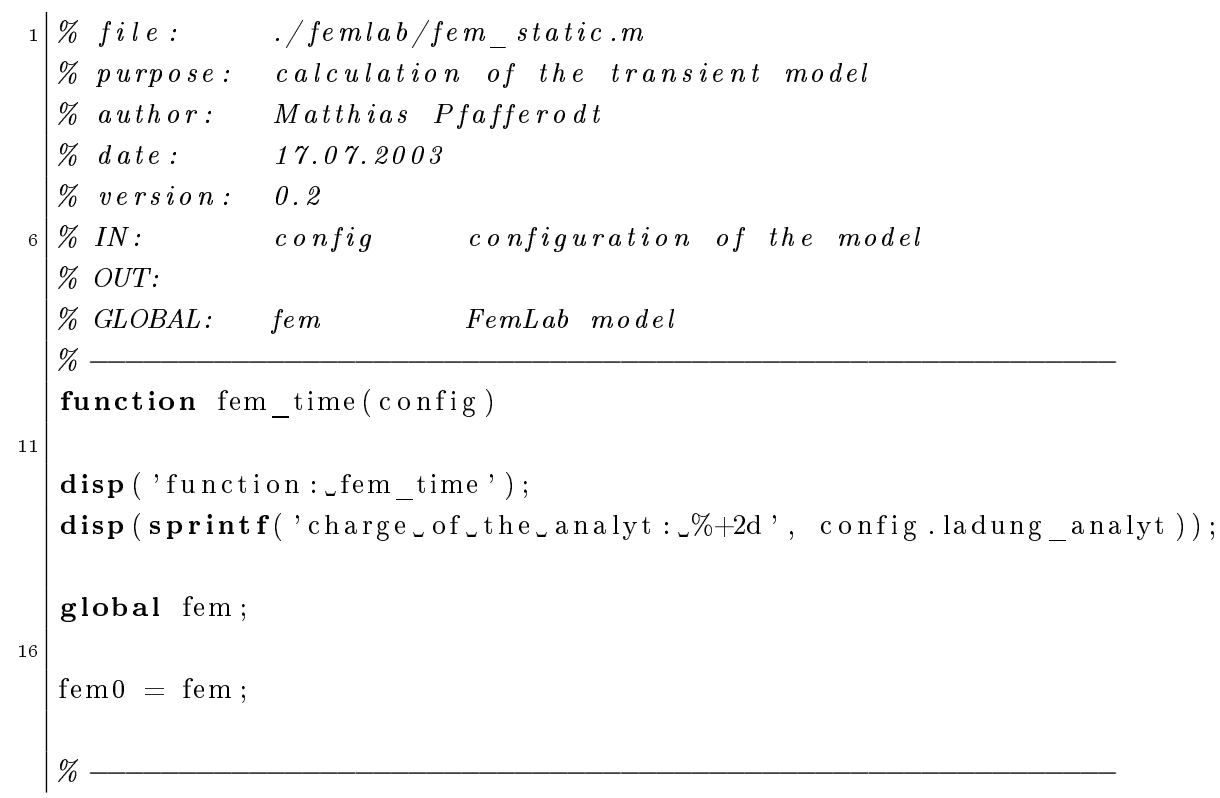




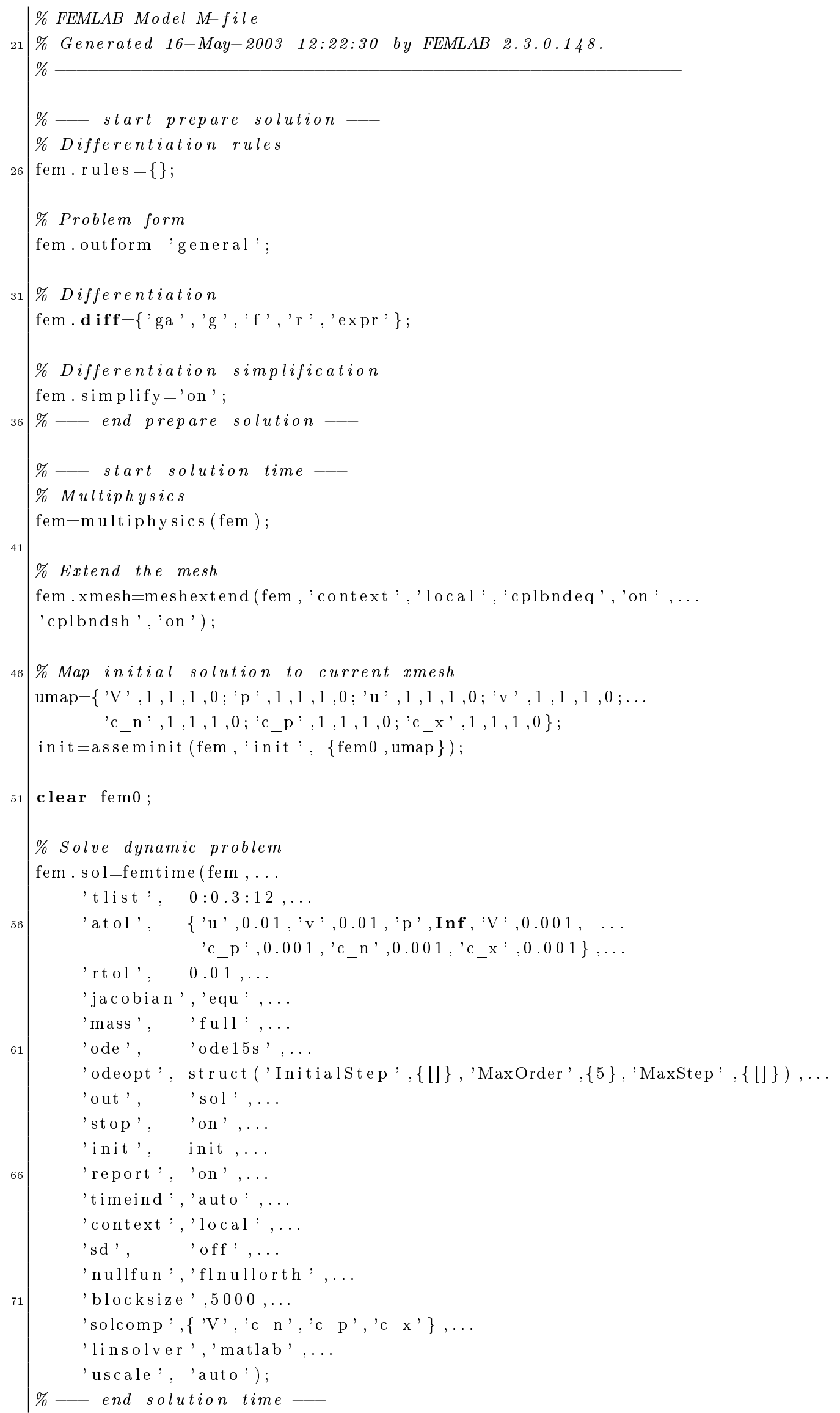




\section{A.9 ./functions/check file.m}

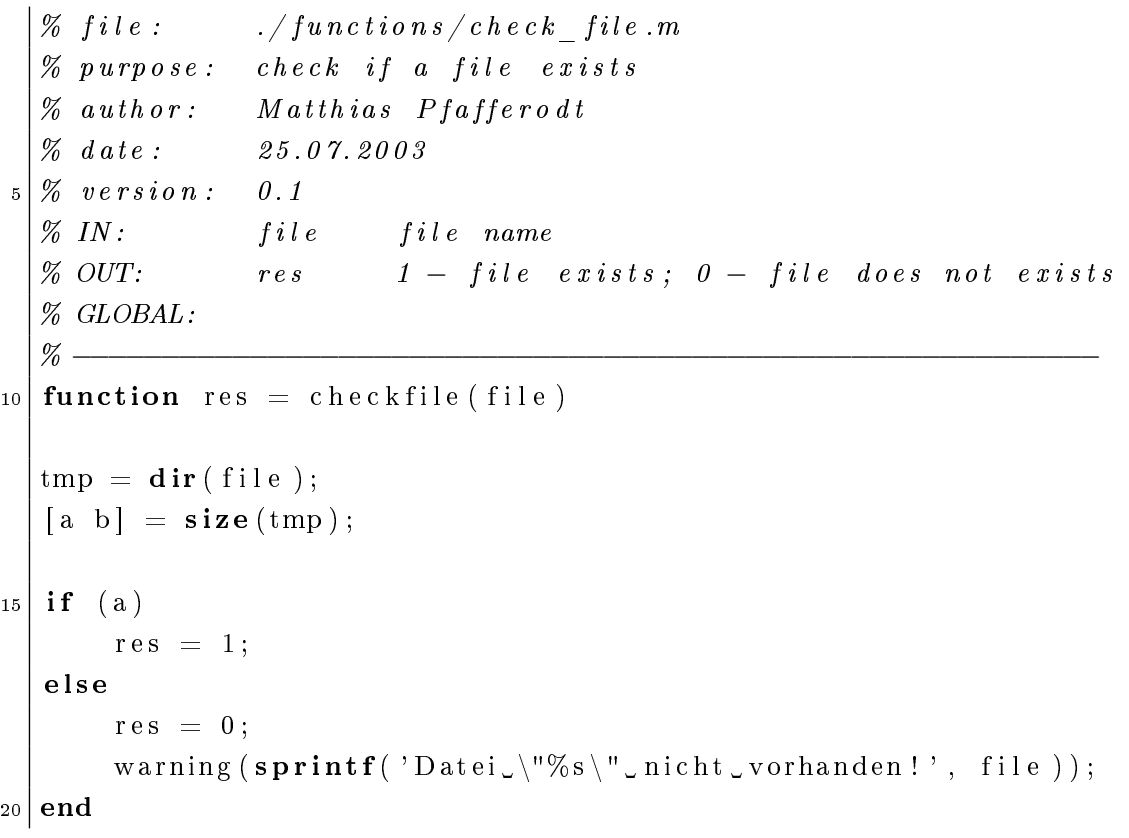

\section{A.10 ./functions/get_var.m}

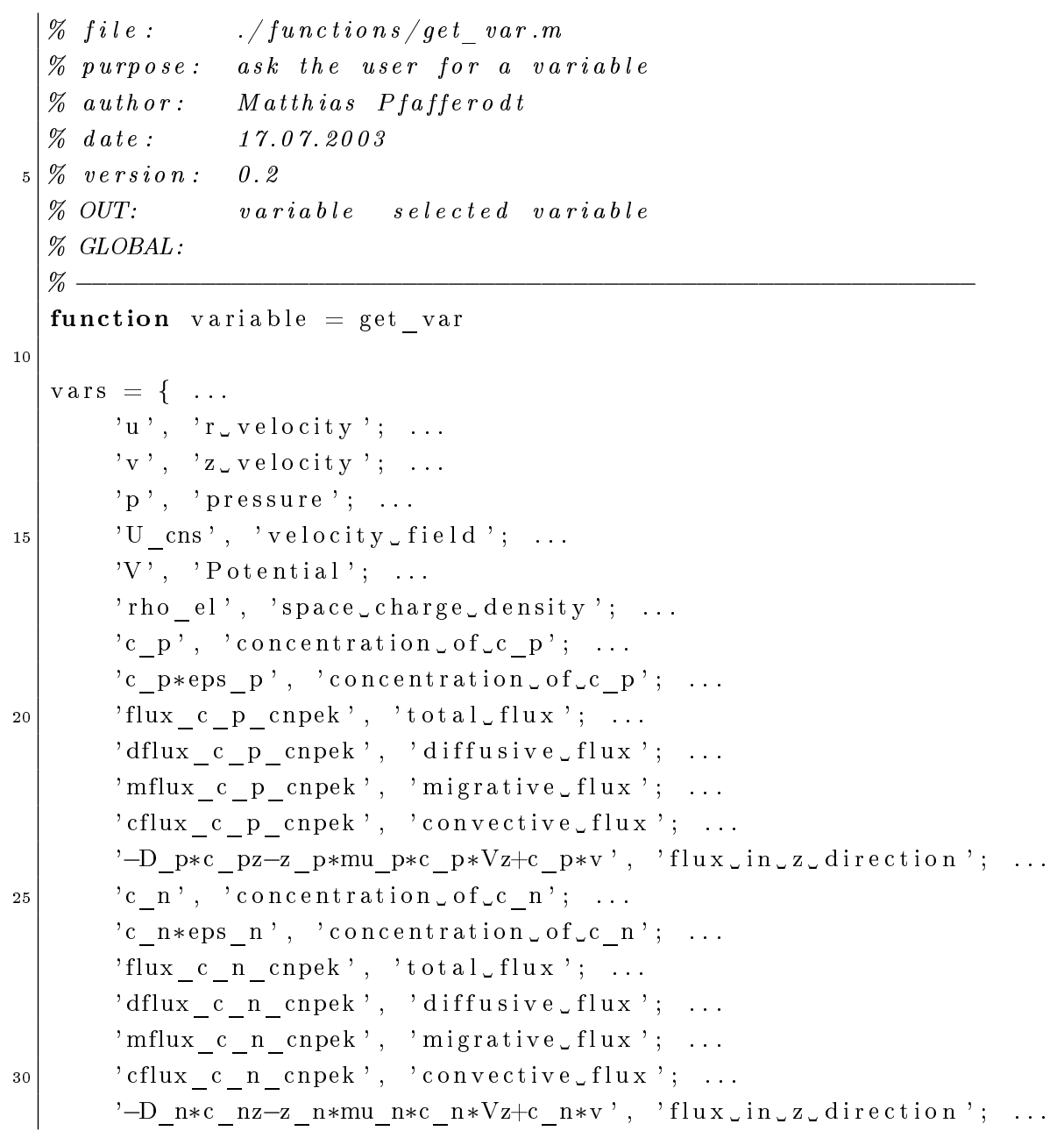




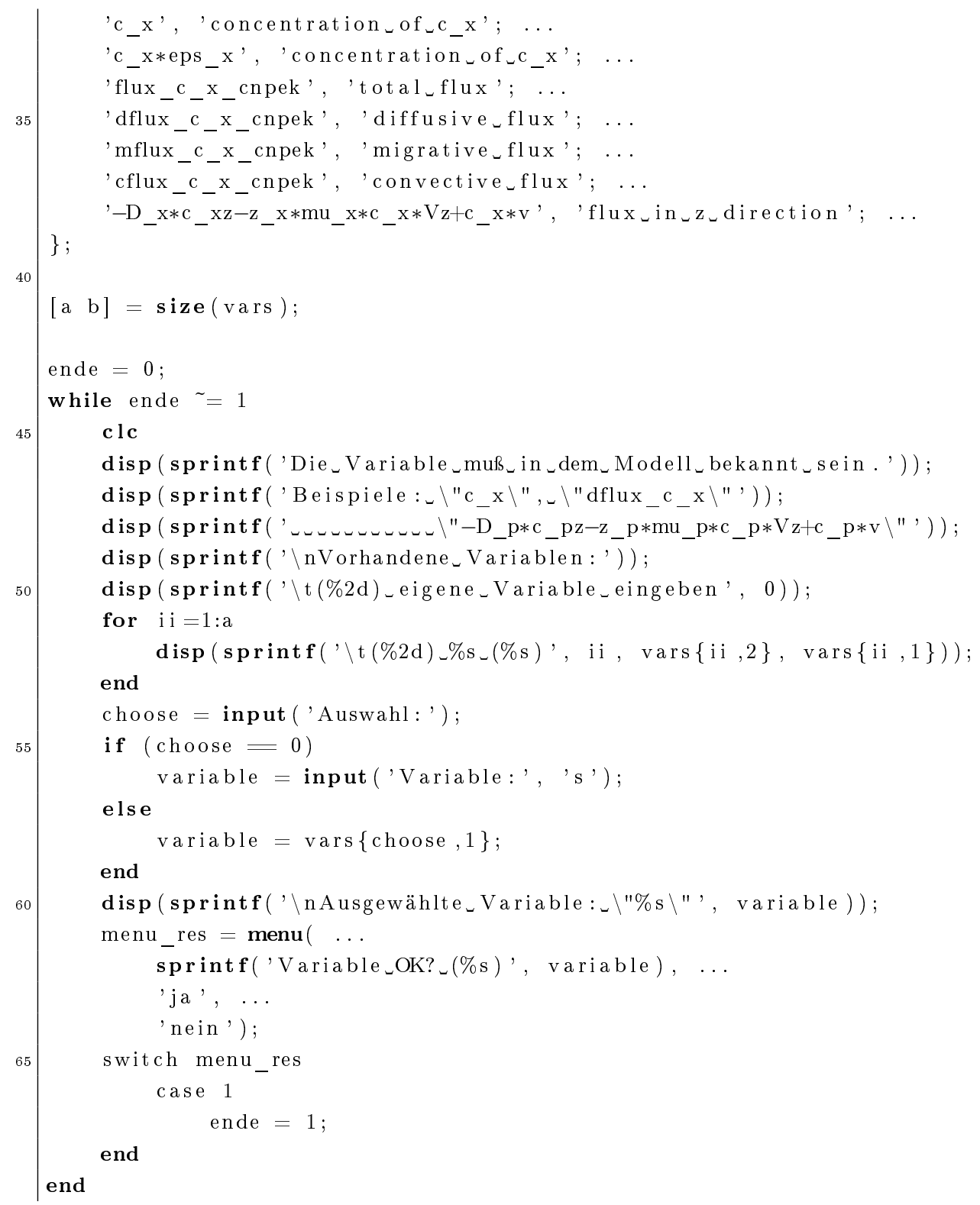

\section{A.11 ./functions/getminmax.m}

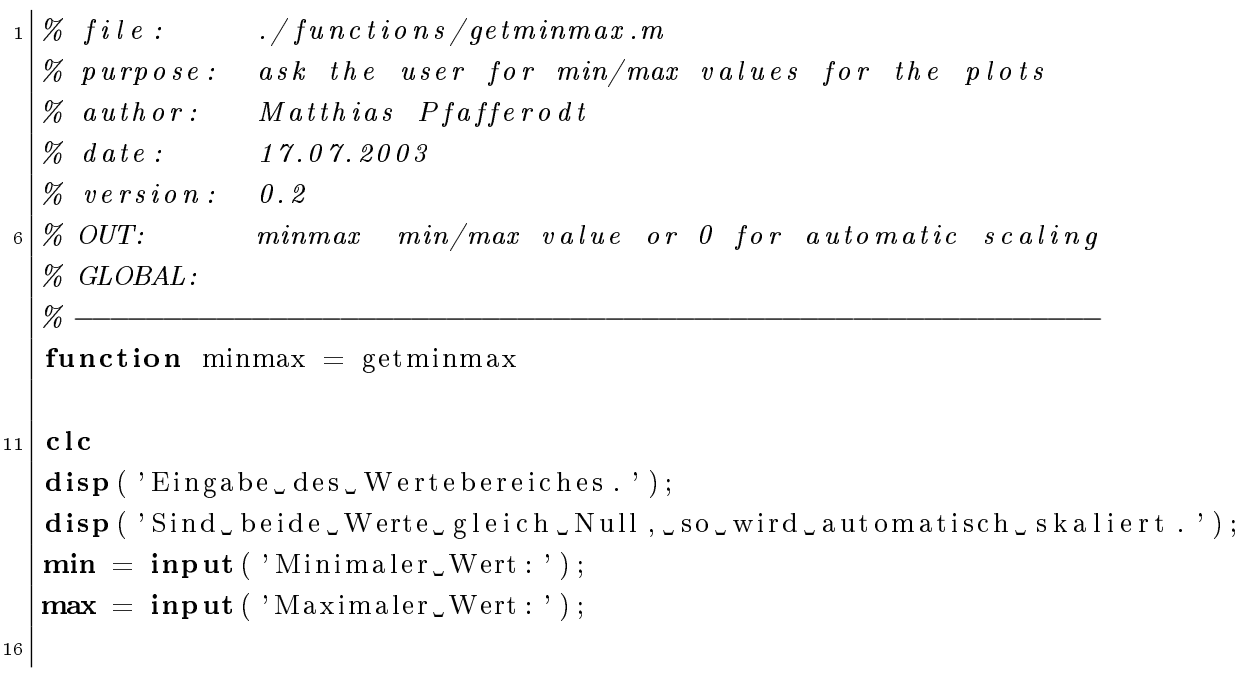




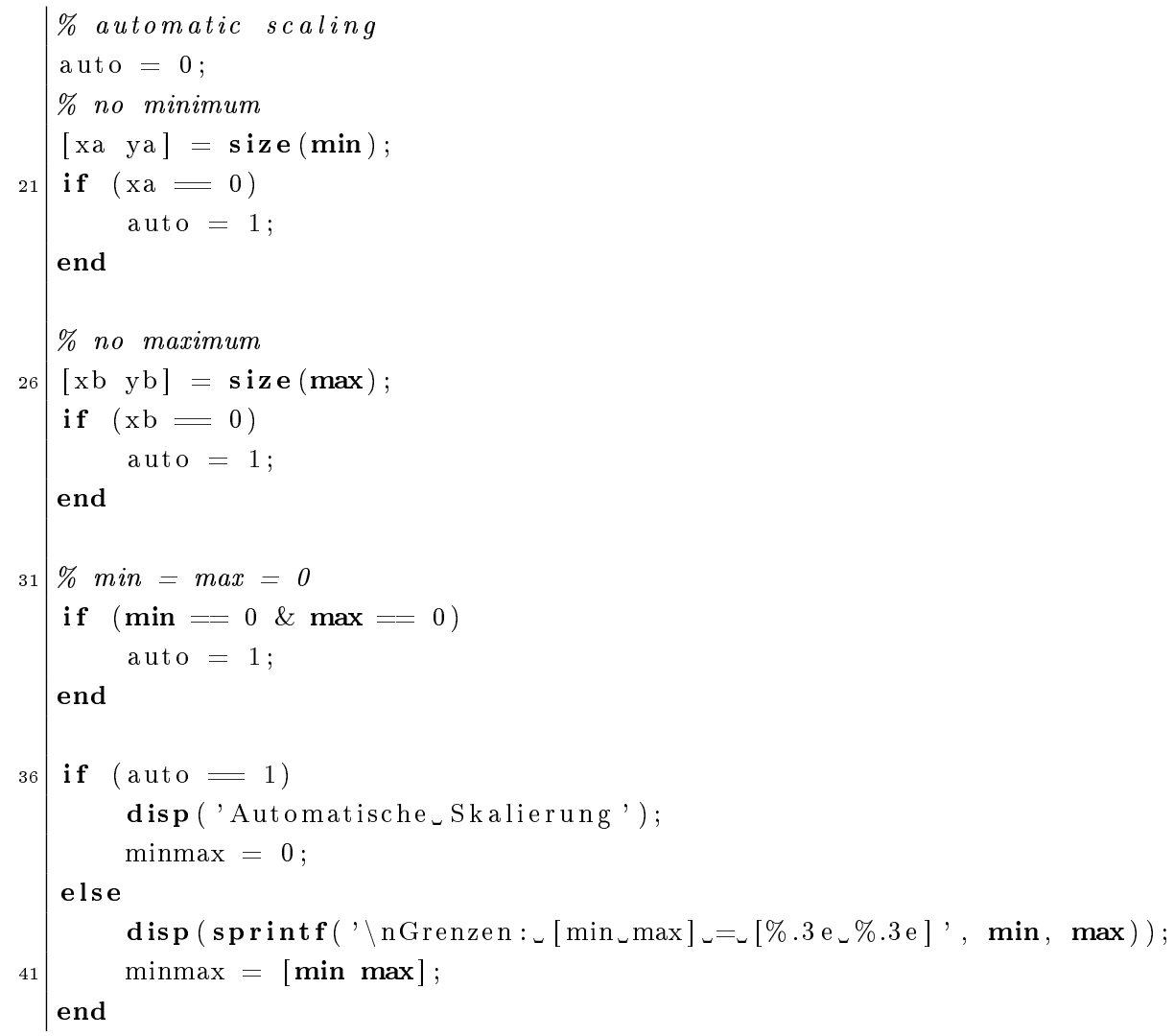

\section{A.12 ./functions/make_dir.m}

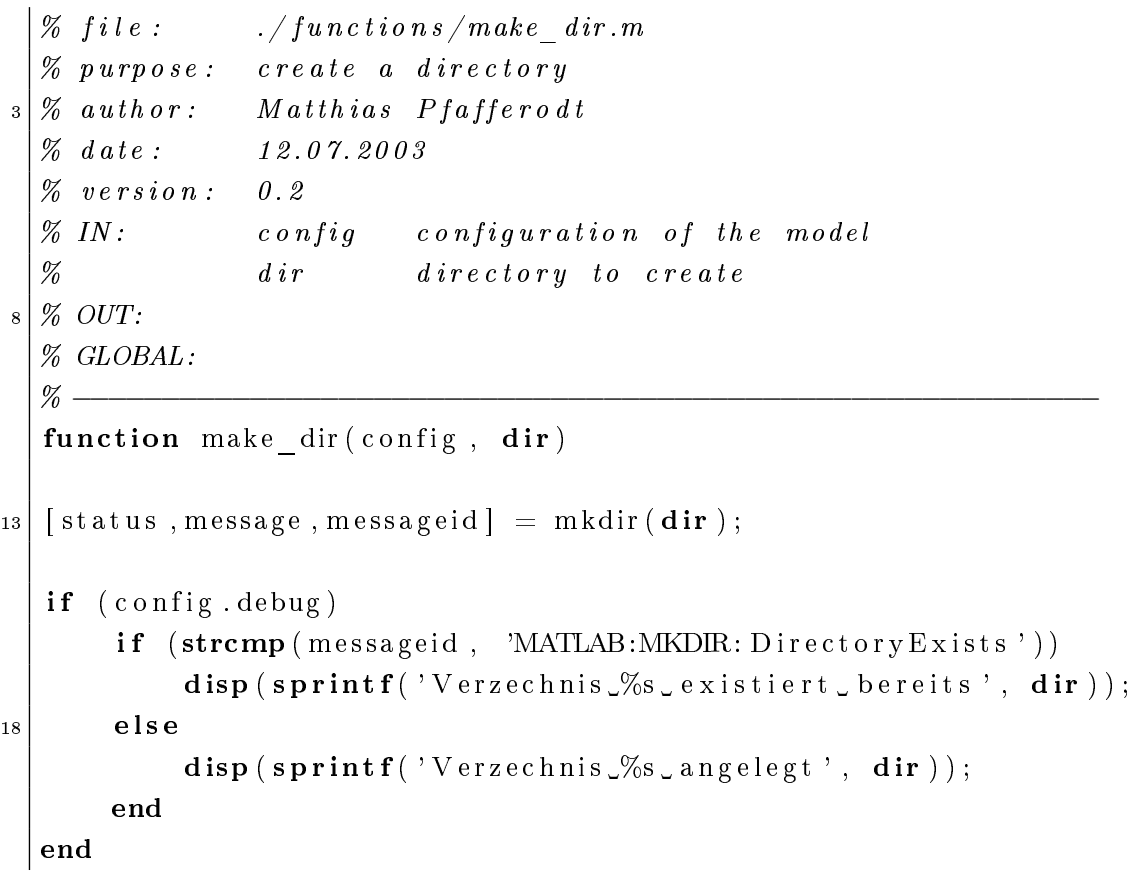

\section{A.13 ./functions/menu_calc.m}

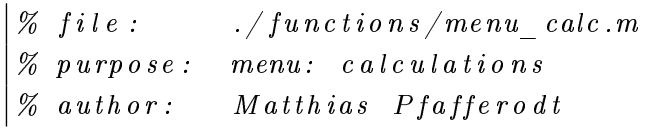






\section{A.14 ./functions/menu_config.m}

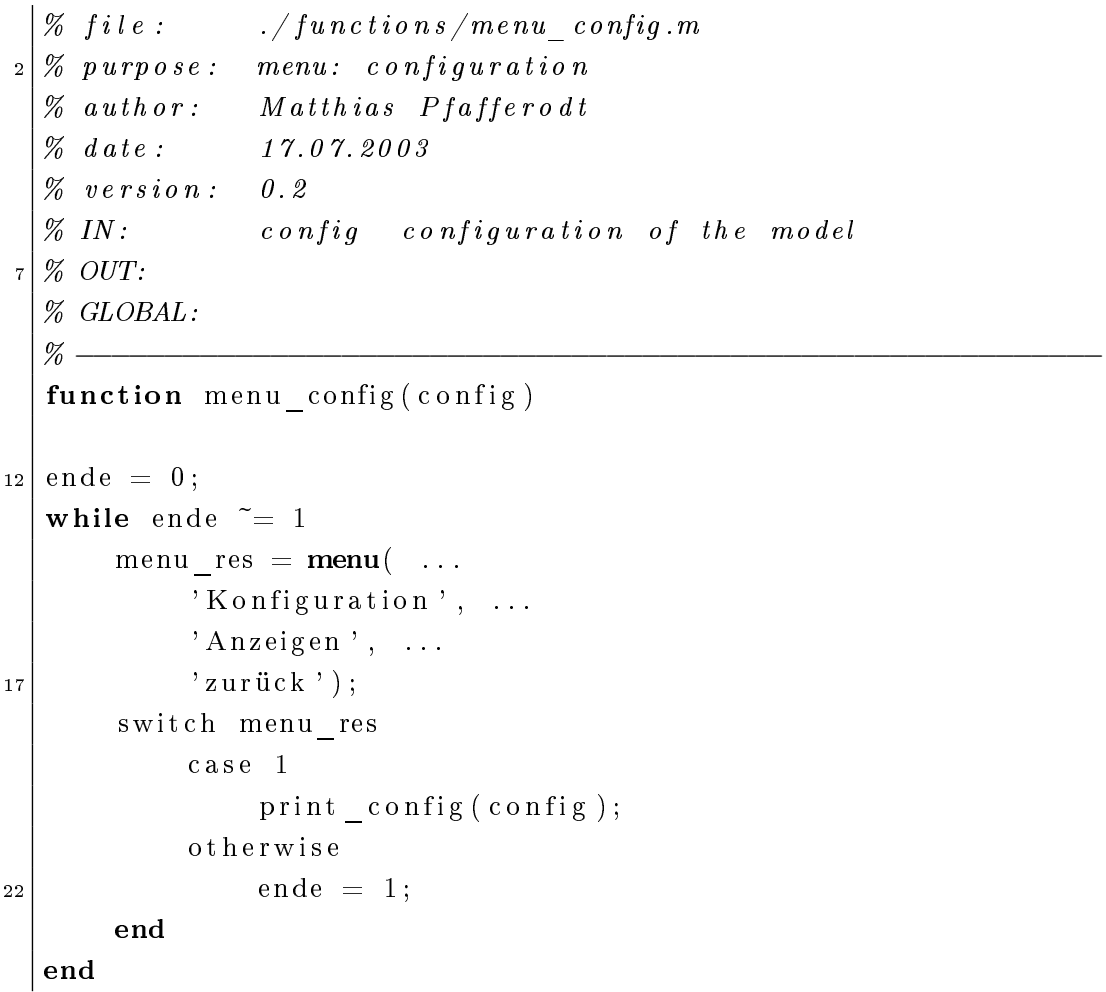

\section{A.15 ./functions/menu_img.m}

$1 \mid \%$ file: $\quad$./functions/menu_img.m 







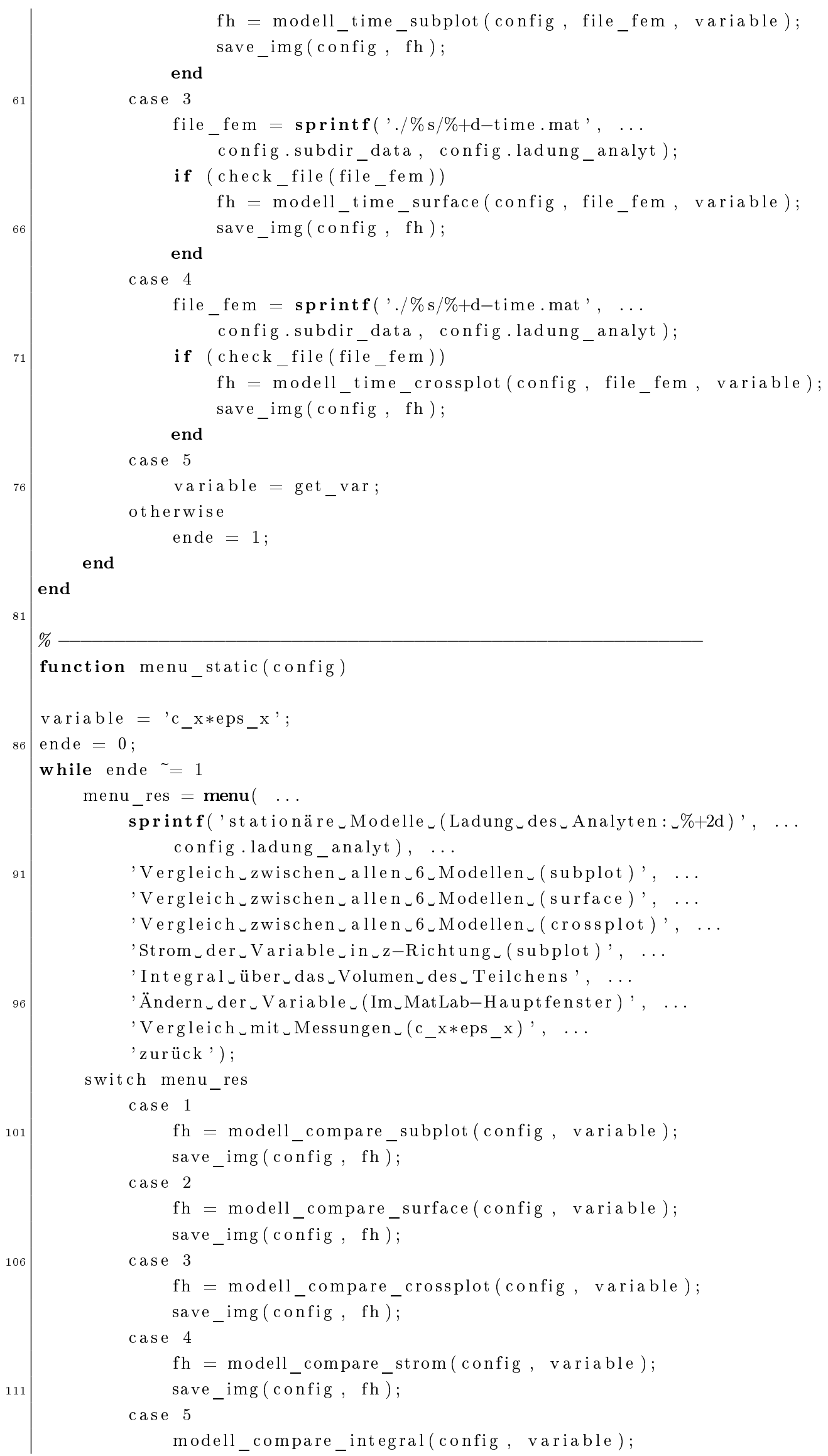




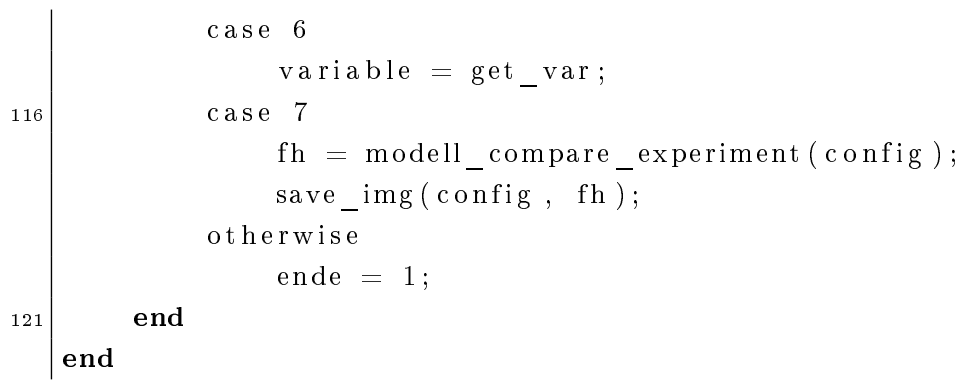

\section{A.16 ./functions/print config.m}

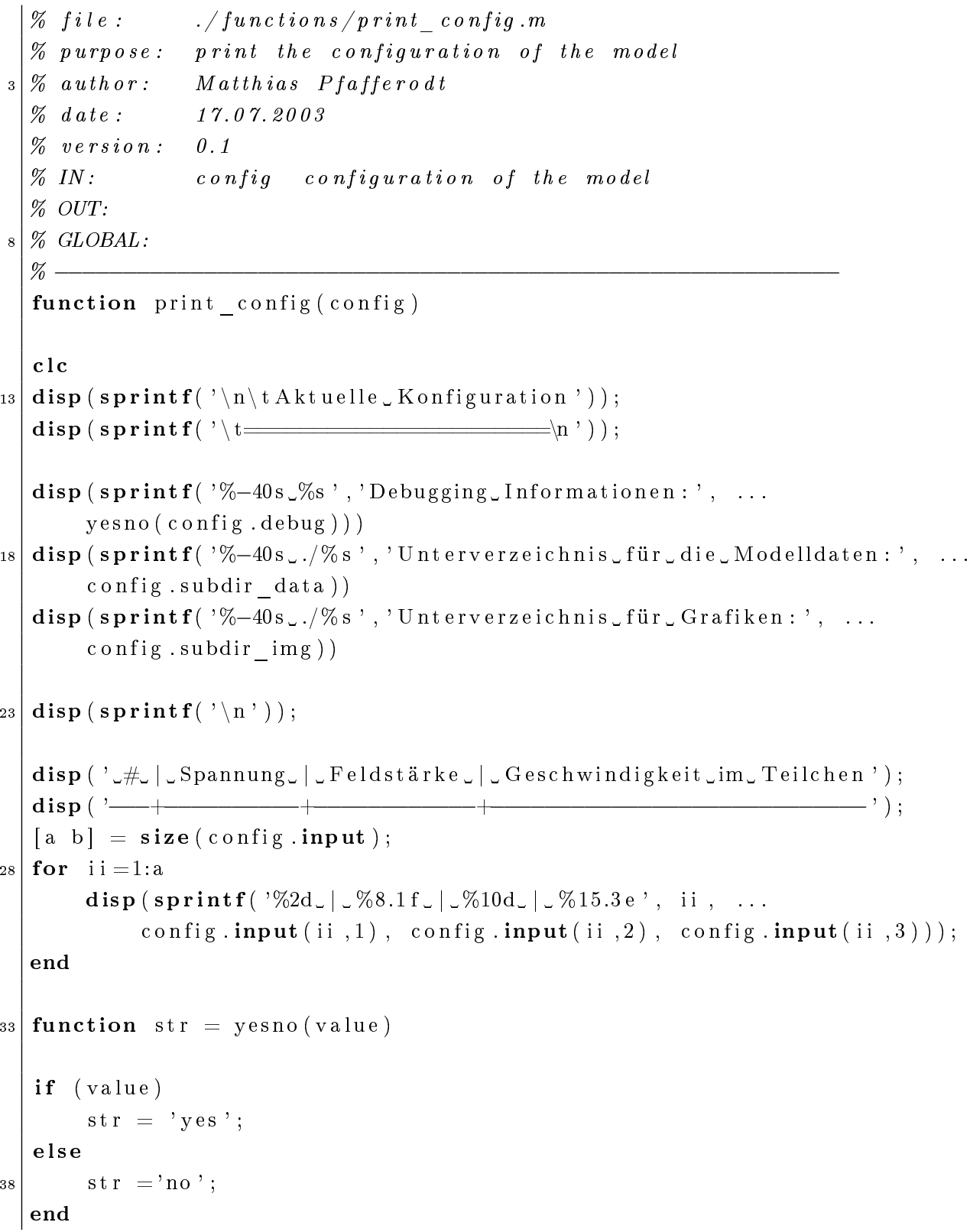

\section{A.17 ./functions/print_img_info.m}








\section{A.18 ./functions/save img.m}

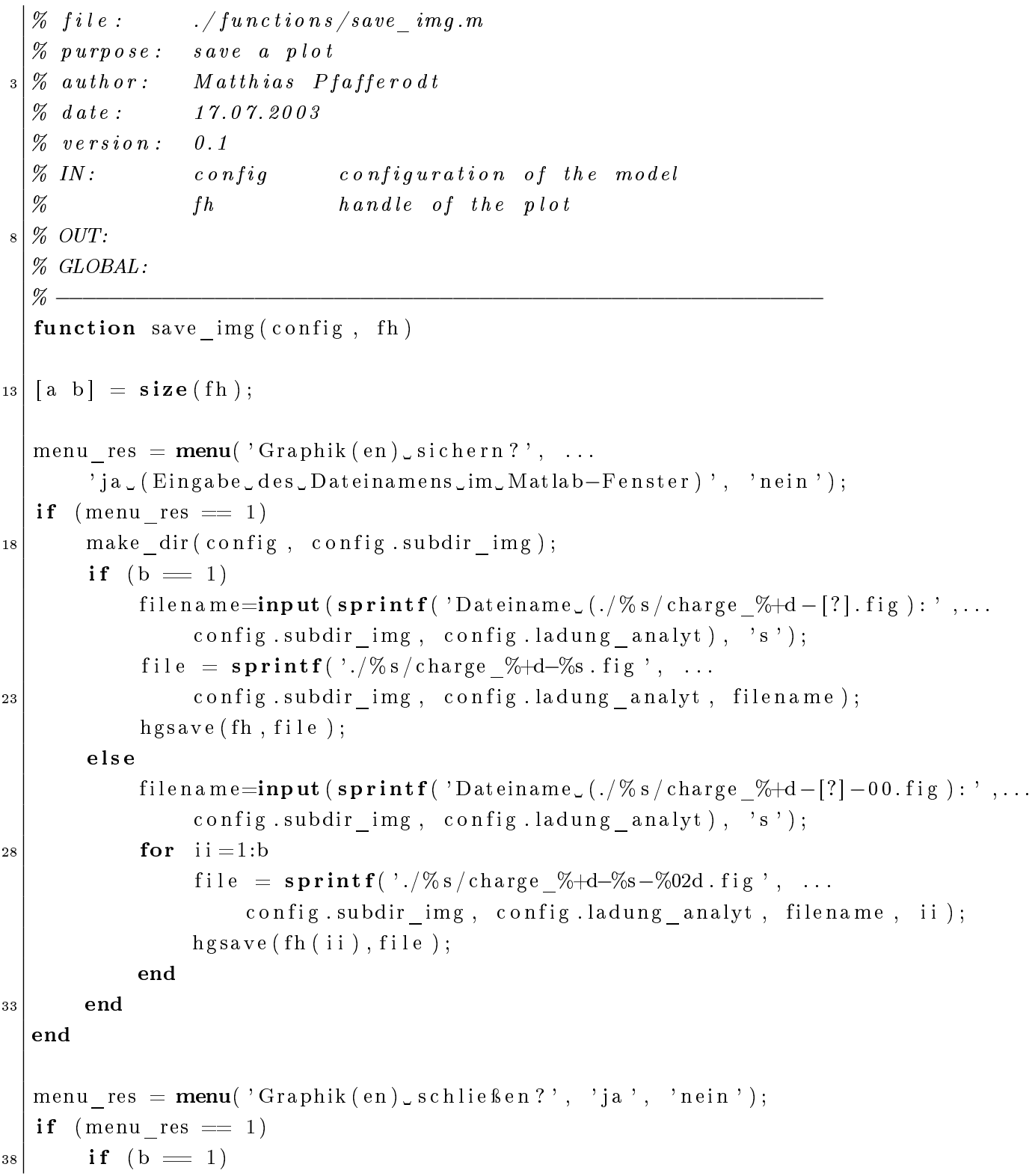




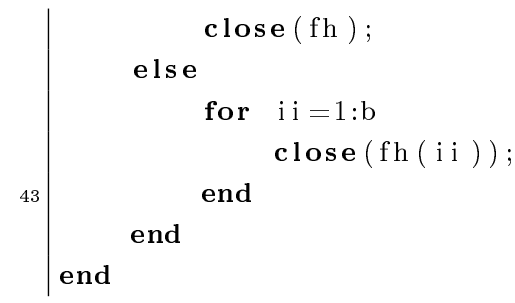

\section{A.19.$/$ modell $/$ modell_compare_crossplot.m}






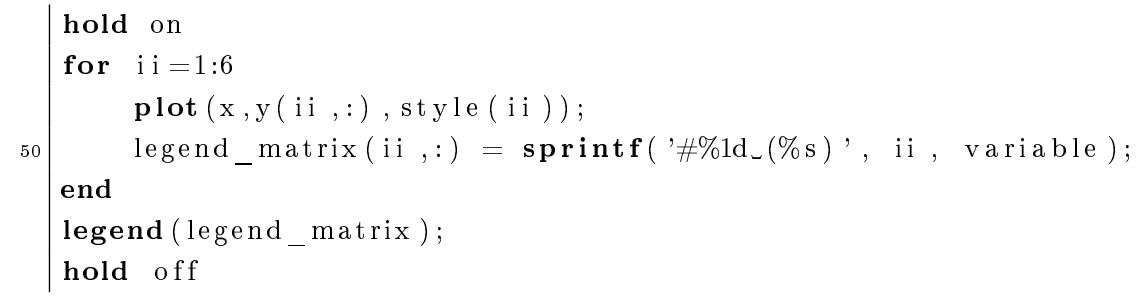

\section{A.20 ./modell/modell_compare_experiment.m}

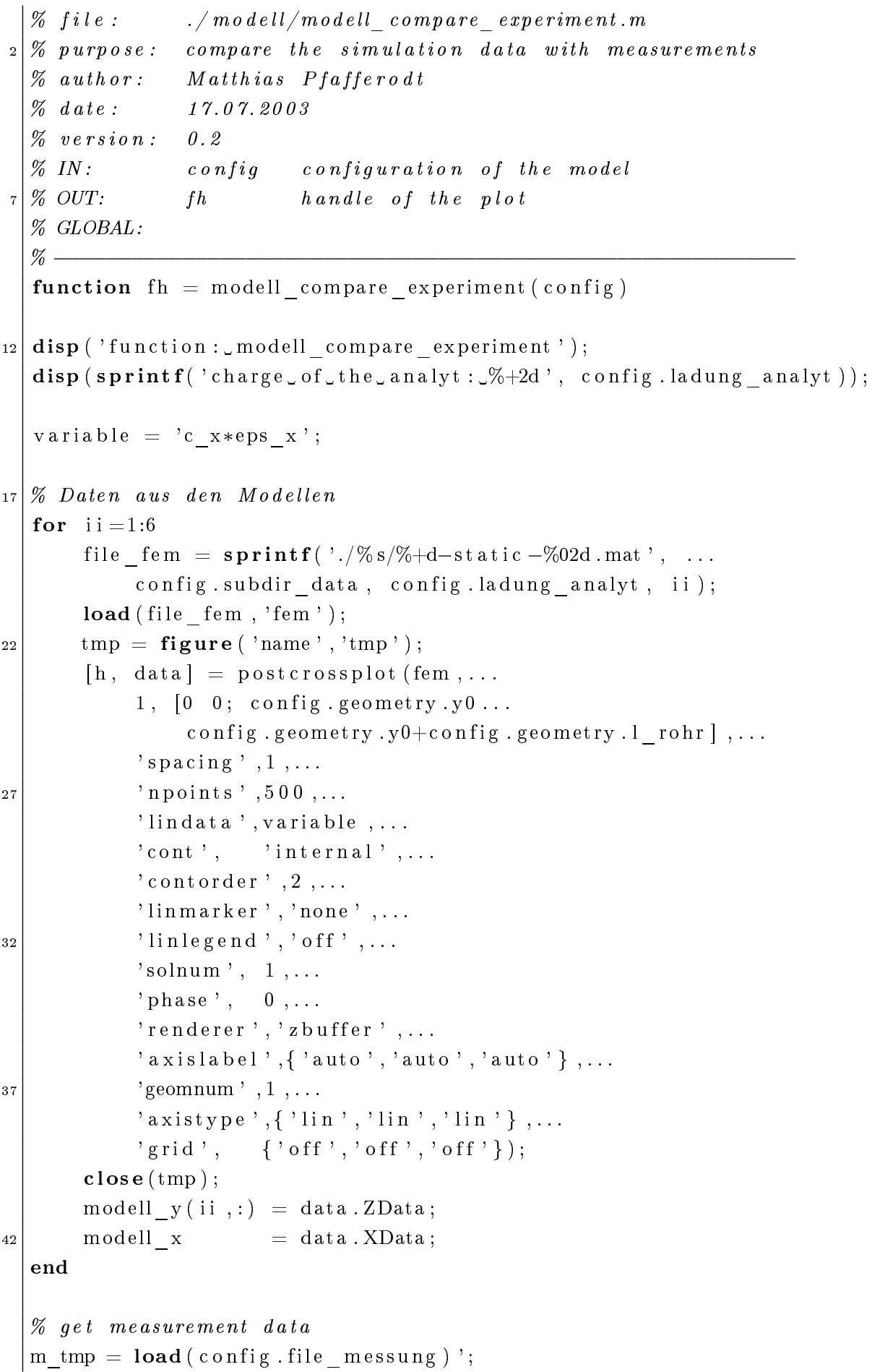




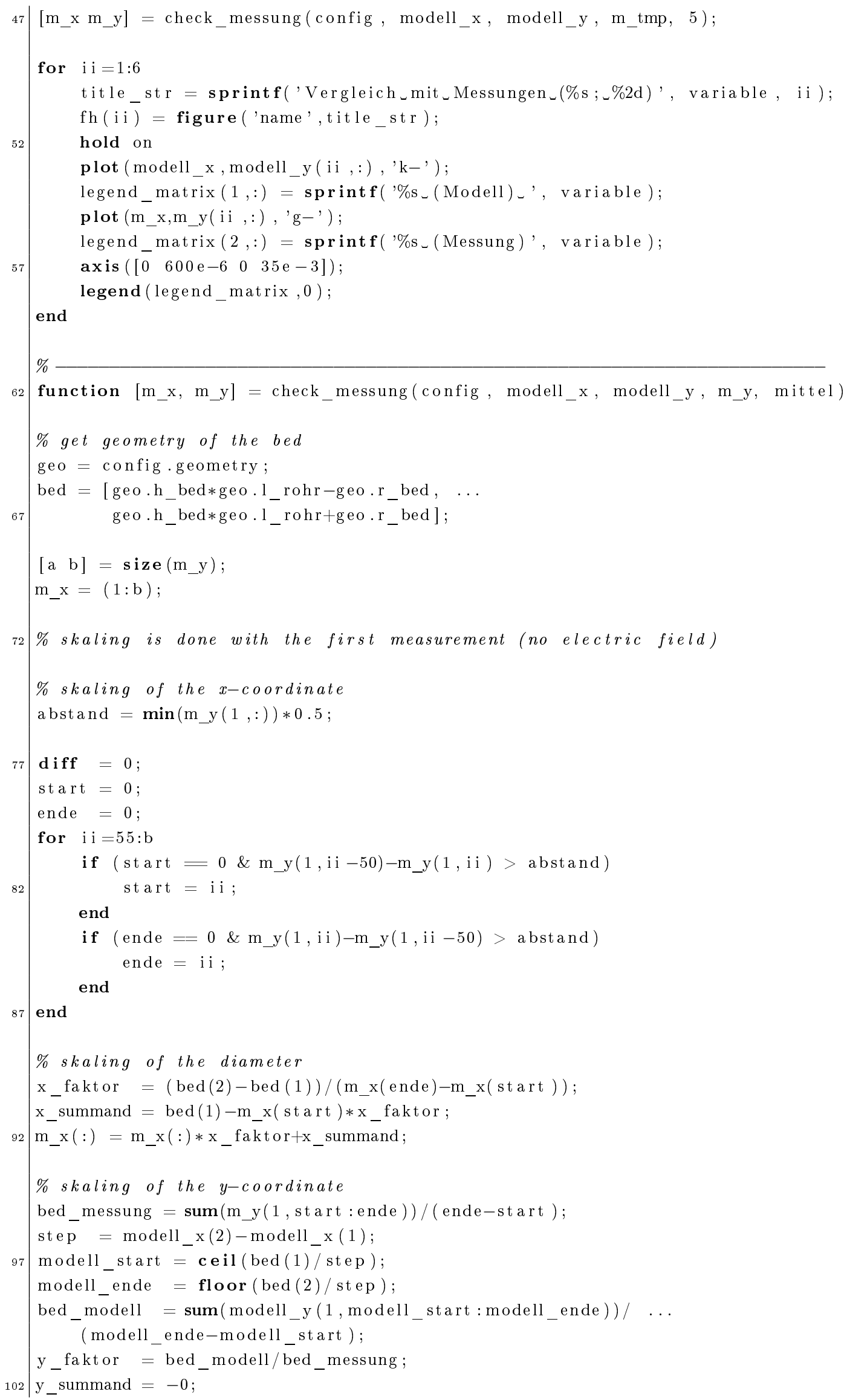


$\mid \mathrm{m} \_\mathrm{y}=\mathrm{m} \_\mathrm{y} \cdot * \mathrm{y} \_$faktor $+\mathrm{y} \_$summand $;$

\section{A.21 ./modell/modell_compare_integral.m}

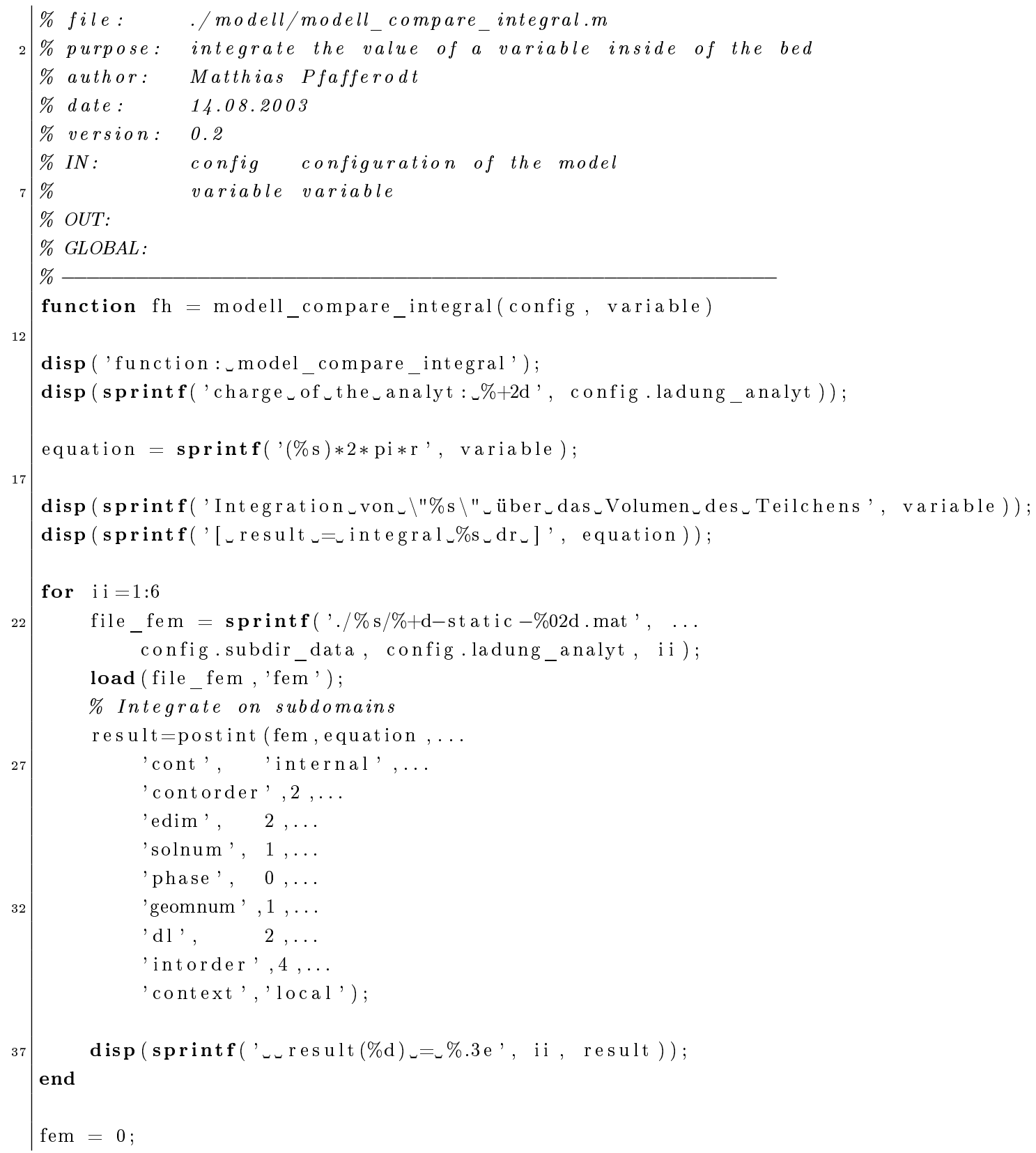

\section{A.22 ./modell/modell compare strom.m}

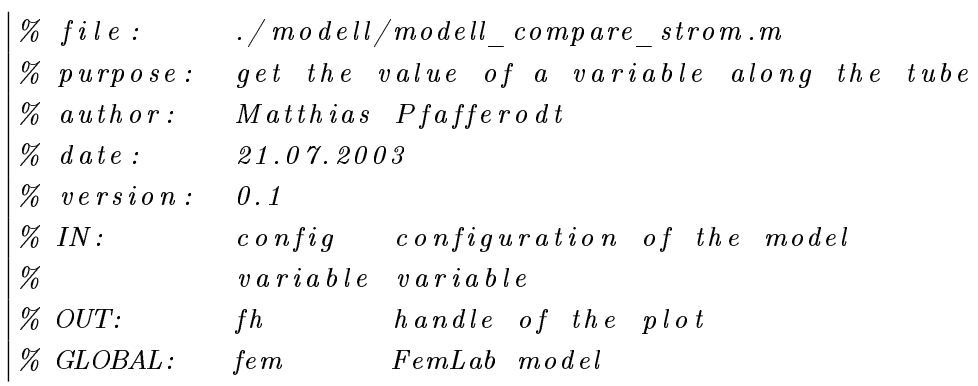




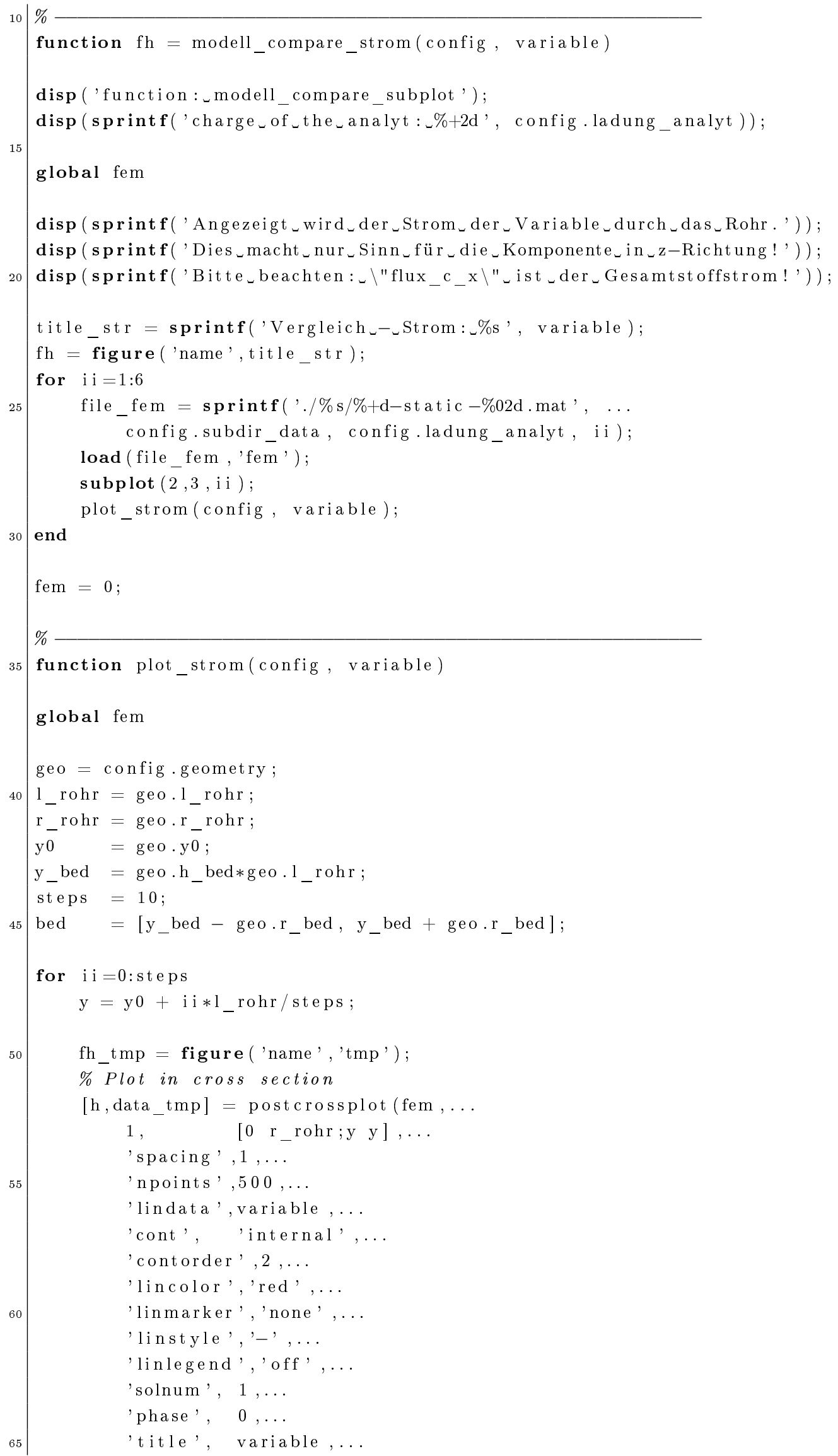




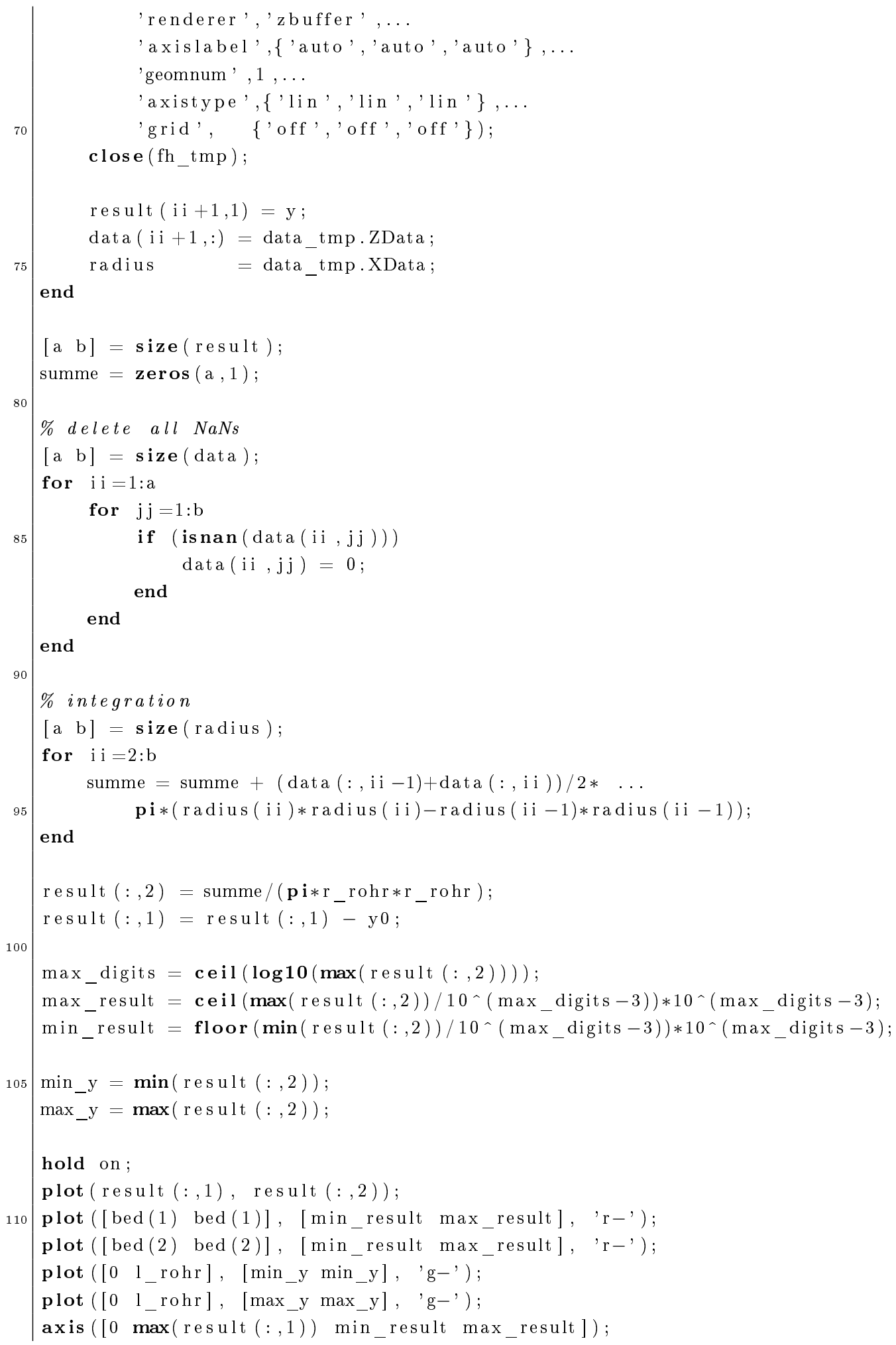

\section{A.23 ./modell/modell compare subplot.m}

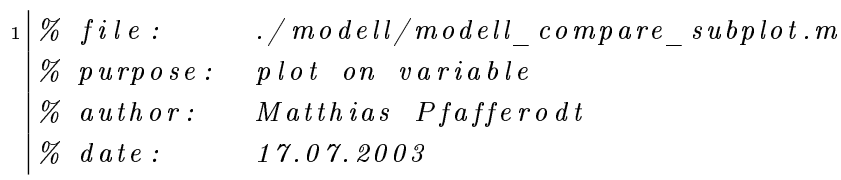




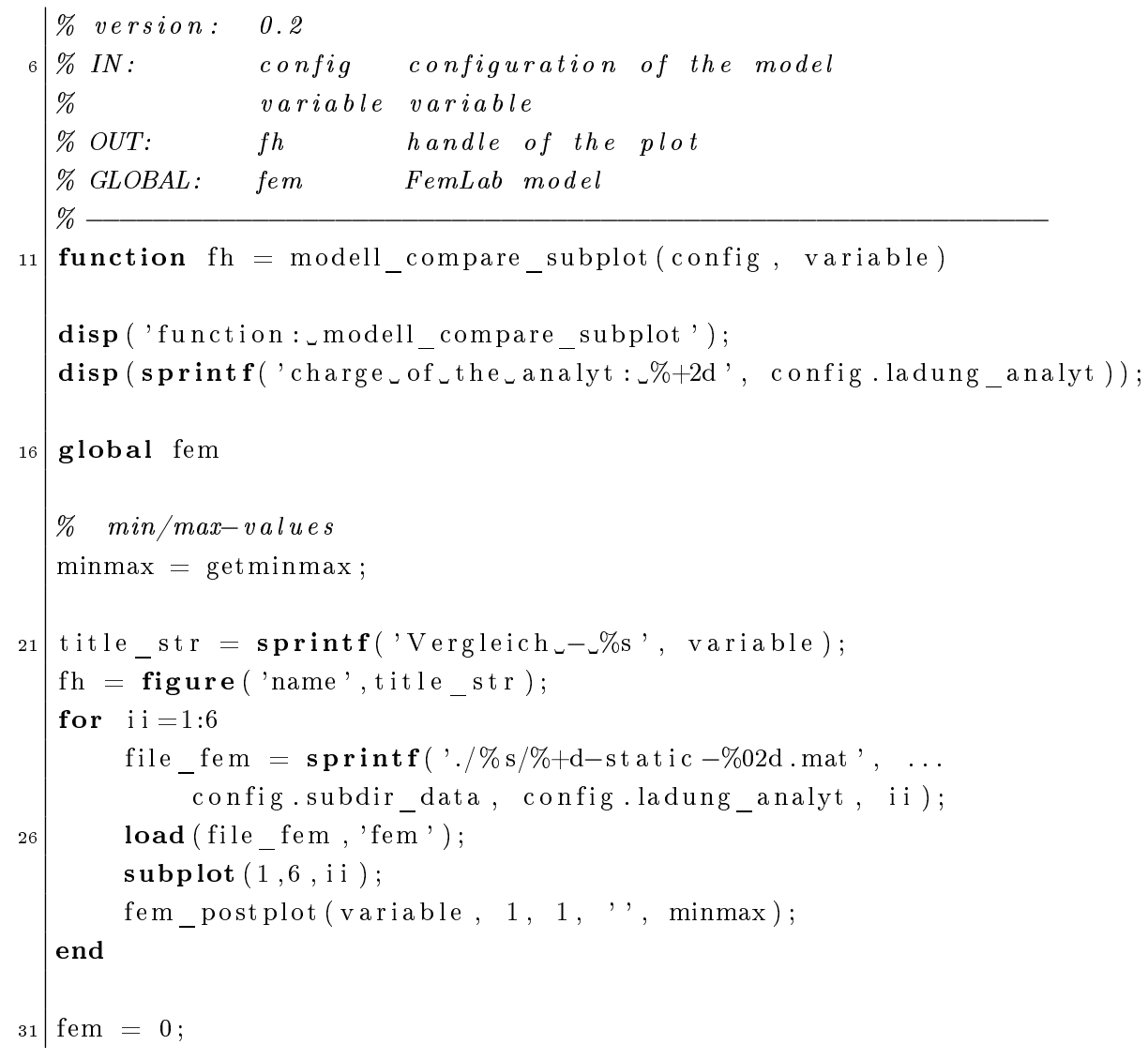

\section{A.24 ./modell/modell_compare_surface.m}

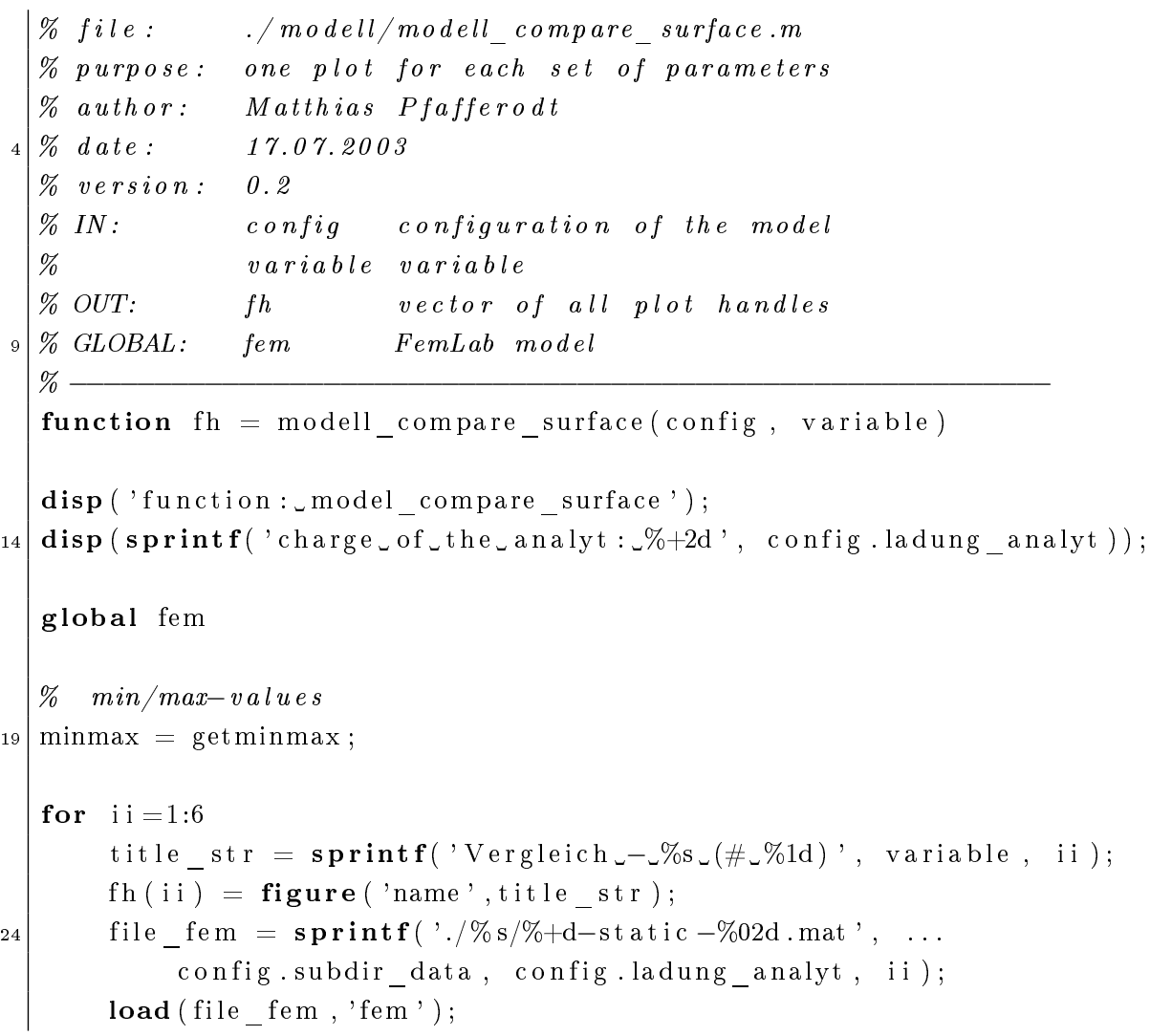




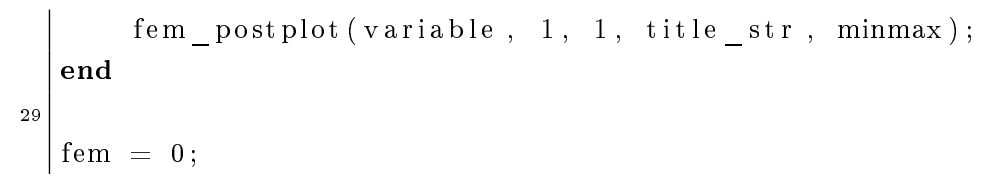

\section{A.25.$/$ modell $/$ modell_time_crossplot.m}

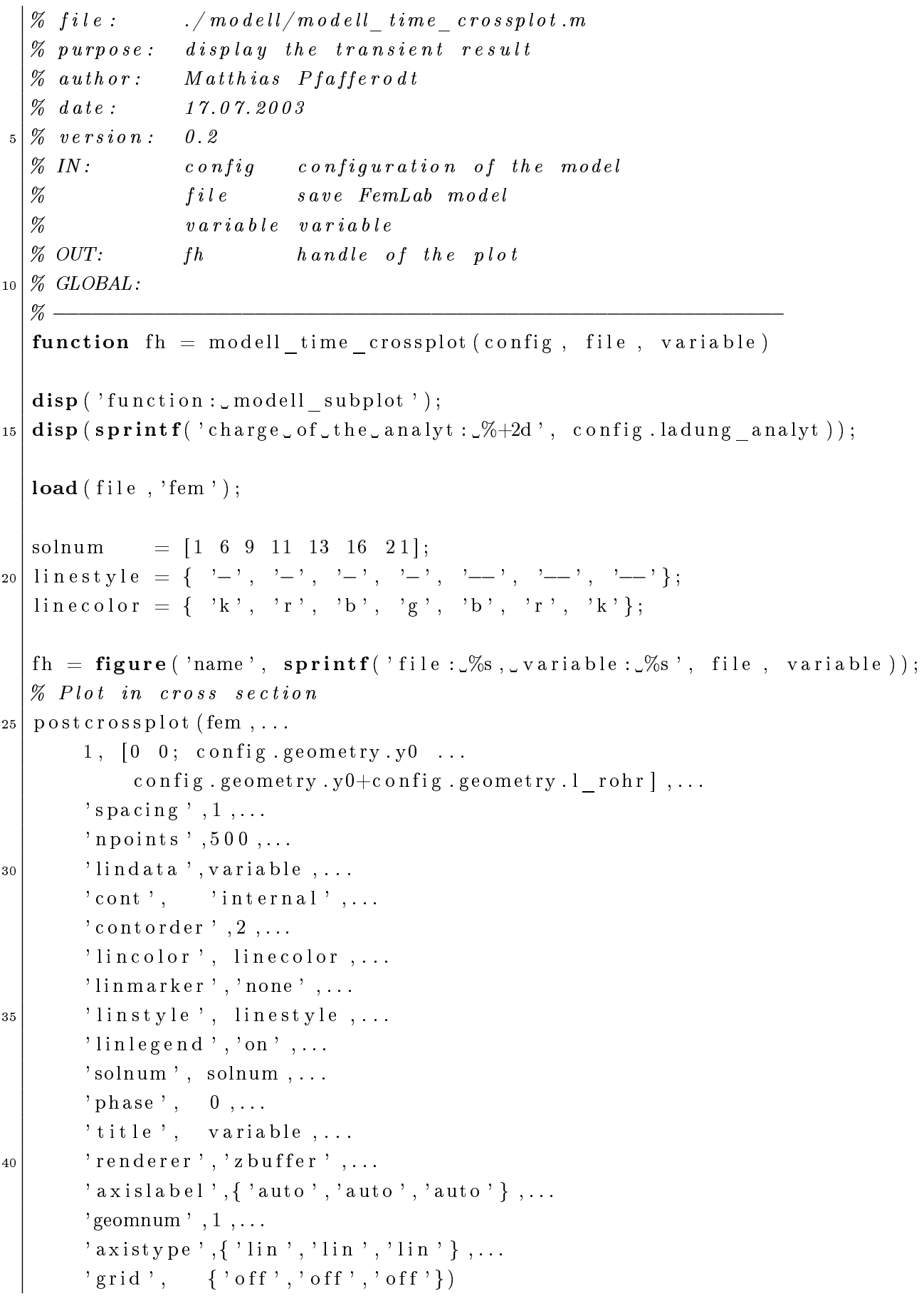

\section{A.26 ./modell/modell_static.m}

\footnotetext{
1 1) file: $\quad . /$ modell/modell_static.m

$\%$ purpose: steady state calculation
} 


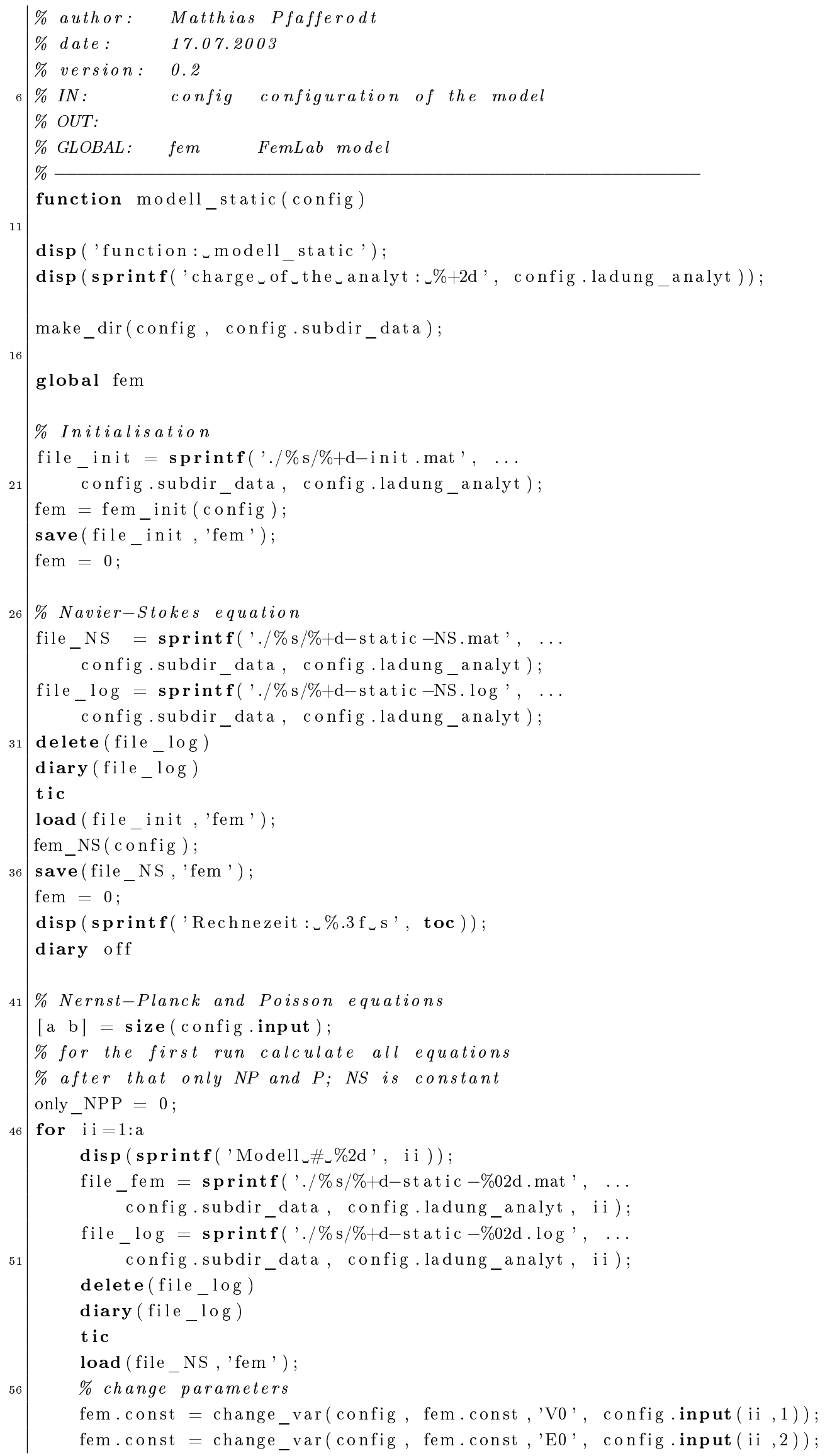




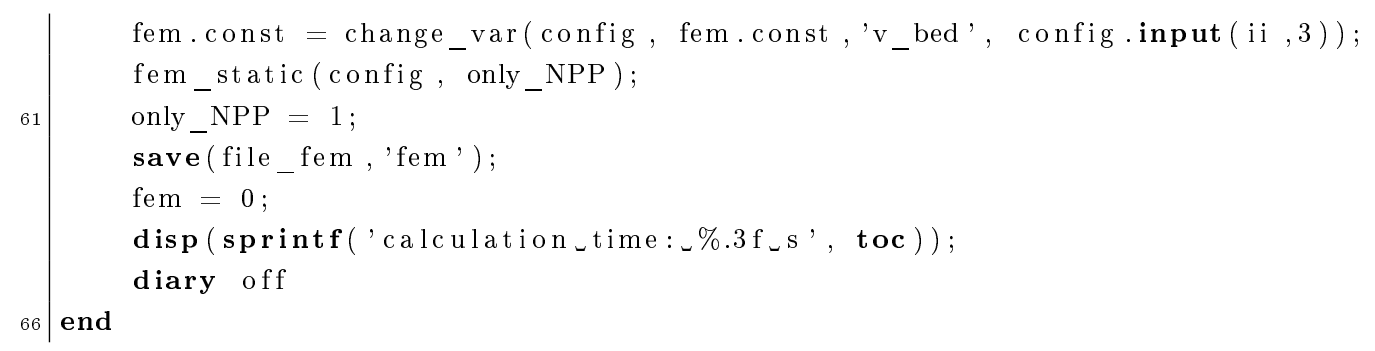

\section{A.27.$/$ modell $/$ modell_time.m}

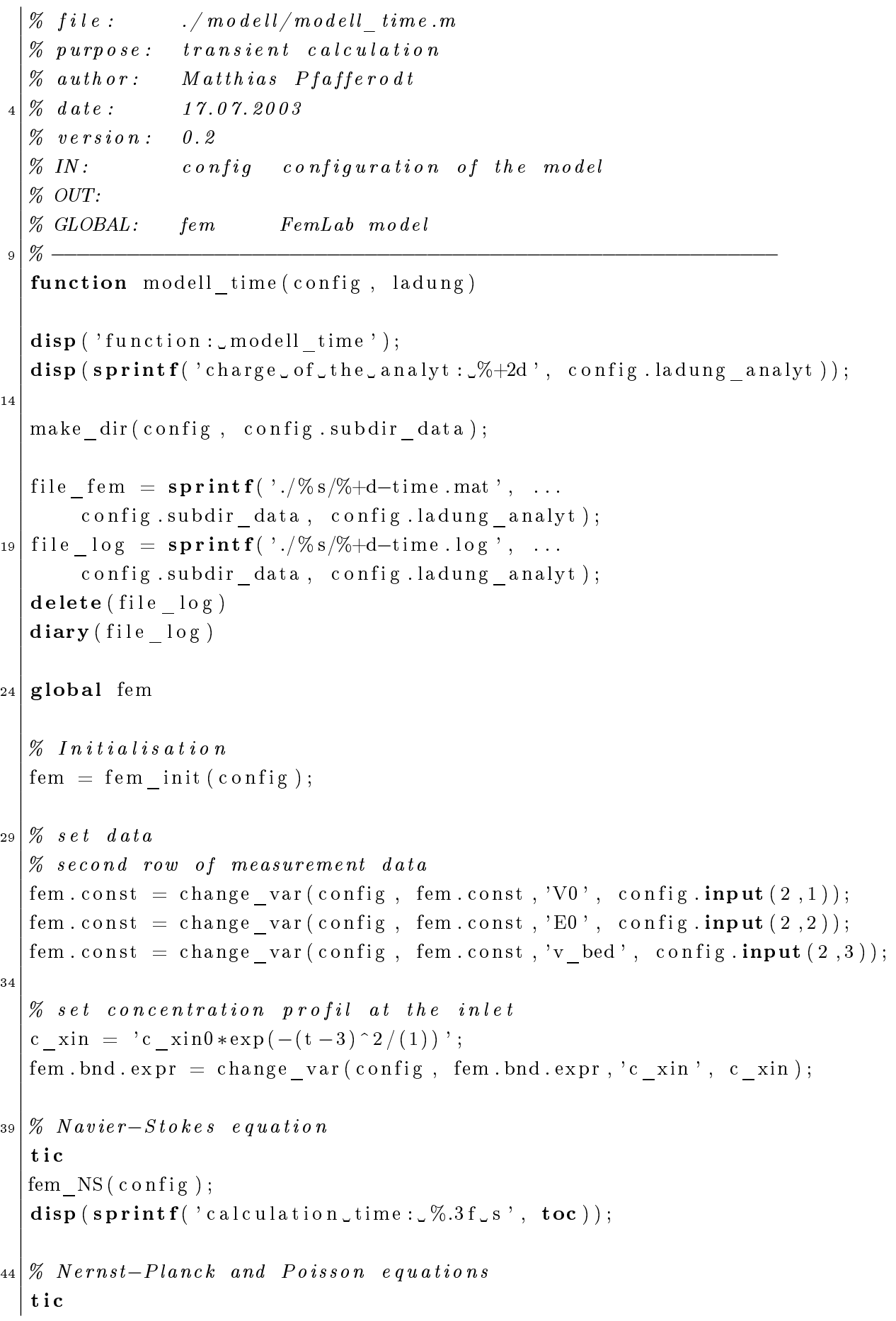




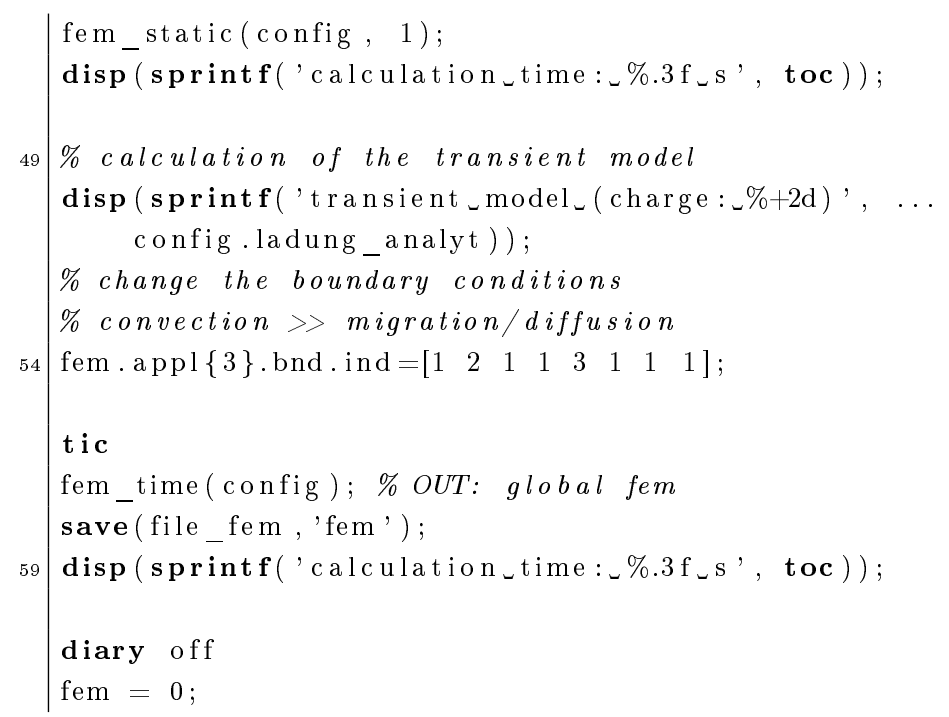

\section{A.28.$/$ modell $/$ modell_time_movie.m}

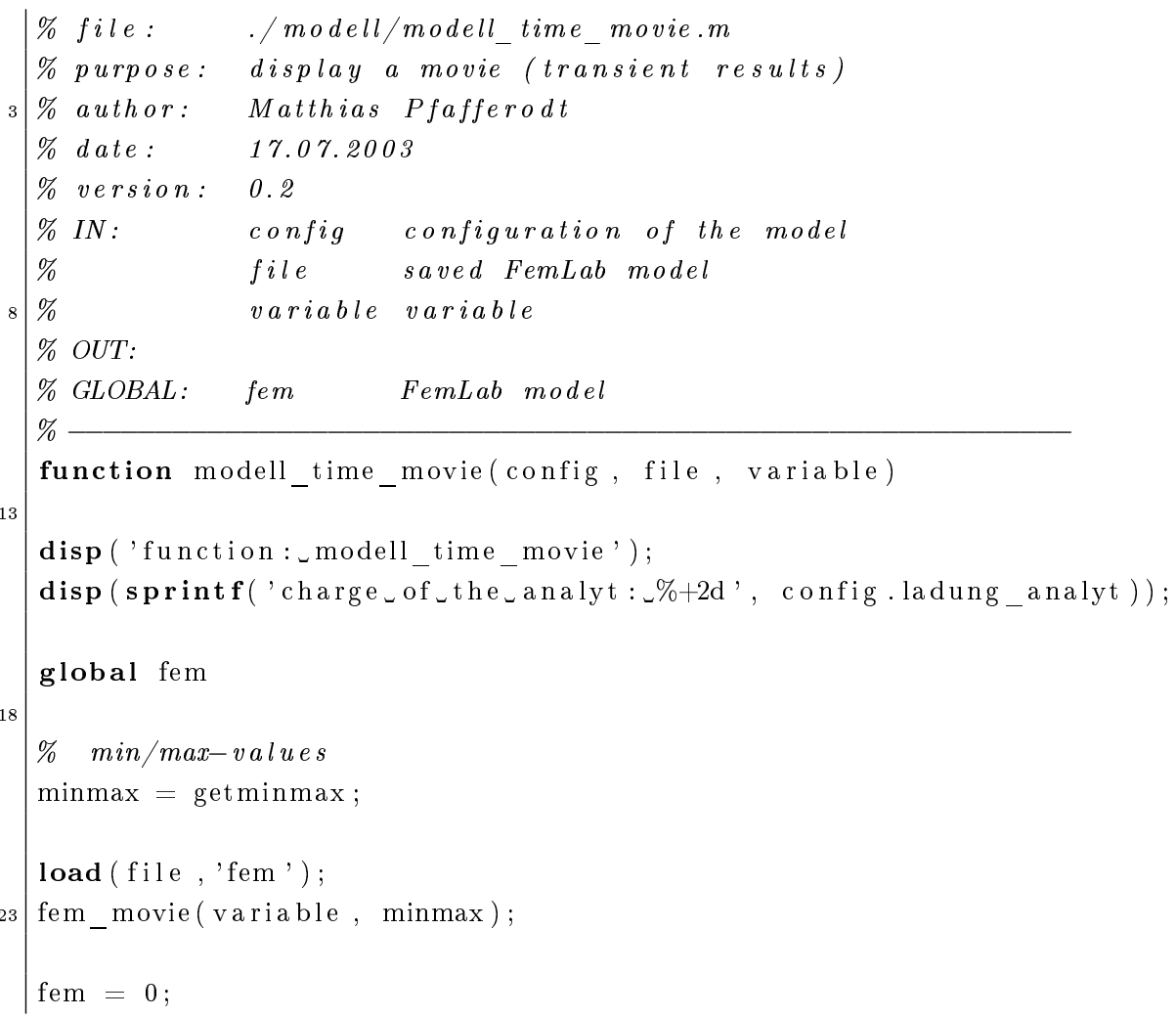

\section{A.29 ./modell/modell time subplot.m}

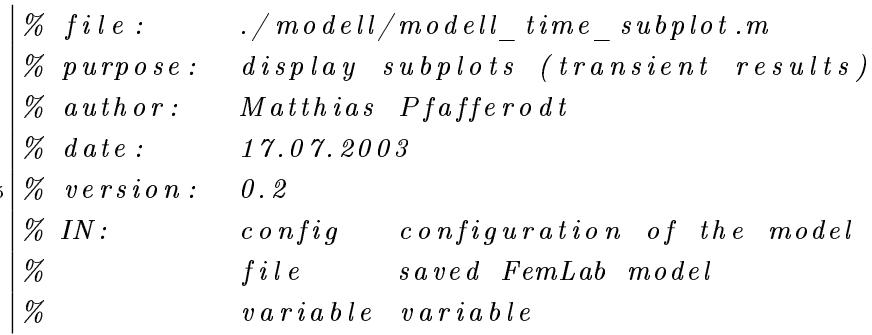




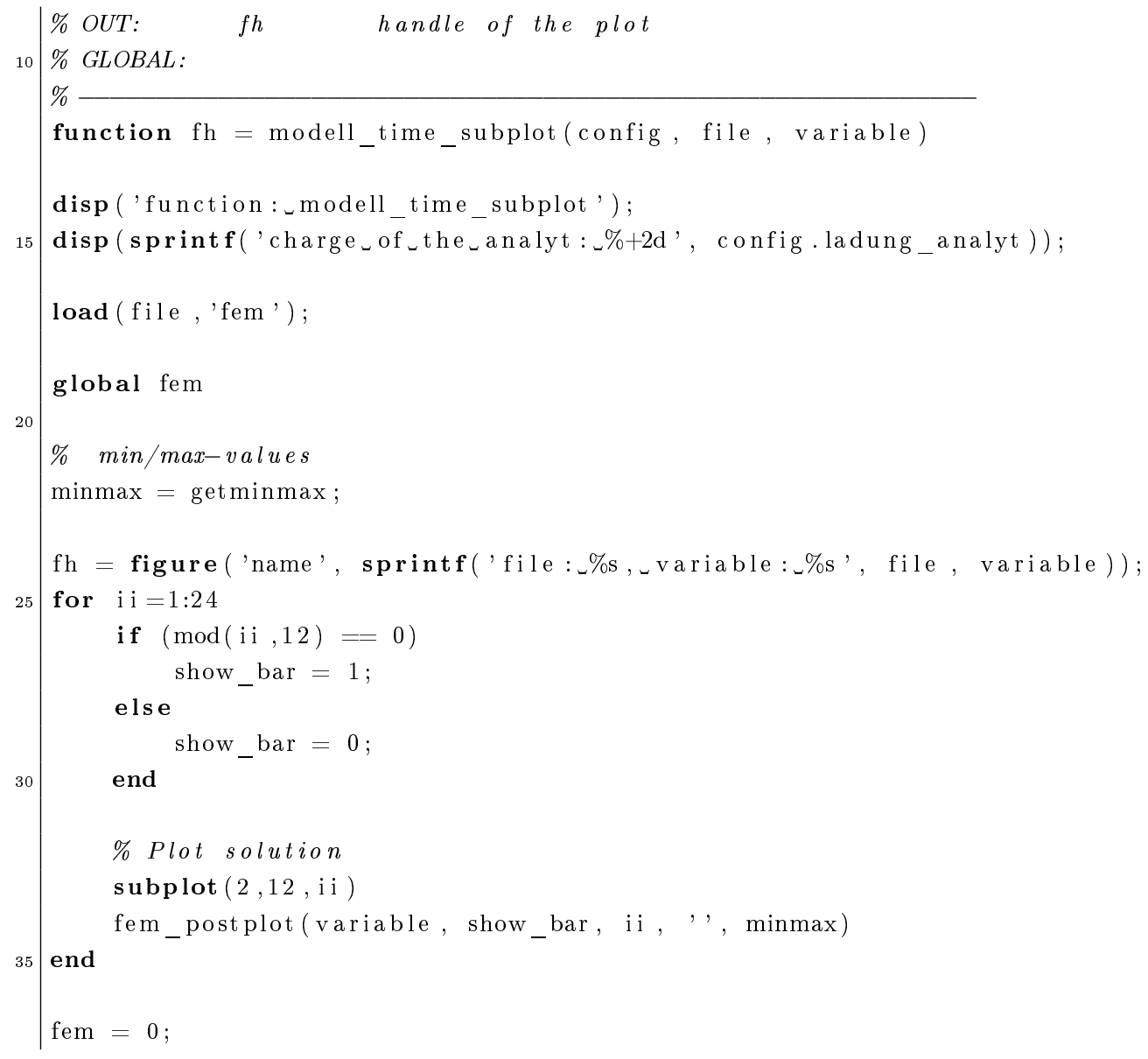

\section{A.30 ./modell/modell_time_surface.m}






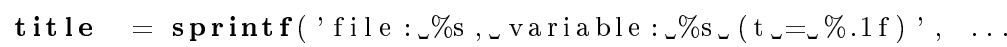

file, variable, $0.3 *(\mathrm{ii}-1))$;

$\mathrm{fh}(\mathrm{ii})=$ figure('name', title);

28 fem_postplot (variable, 1, ii, title, minmax)

end

fem $=0 ;$ 